\title{
Caspase activation and apoptosis in response to proteasome inhibitors
}

\author{
CJ Henderson ${ }^{1,2}$, E Aleo ${ }^{1,2}$, A Fontanini ${ }^{1,2}$, R Maestro ${ }^{3}$, \\ G Paroni $^{1,2}$ and $C$ Brancolini ${ }^{\star, 1,2}$ \\ 1 MATI Center of Excellence, Universita' di Udine. P.le Kolbe 4, Udine 33100, \\ Italy \\ 2 Dipartimento di Scienze e Tecnologie Biomediche, Sezione di Biologia, \\ Universita' di Udine. P.le Kolbe 4, Udine 33100, Italy \\ 3 MMNP-Unit Experimental Oncology CRO-IRCCS, National Cancer Institute, \\ Via Pedemontana Occ. 12, Aviano (PN) 33081, Italy \\ * Corresponding author: C Brancolini, Dipartimento di Scienze e Tecnologie \\ Biomediche, Sezione di Biologia, Universita' di Udine. P.le Kolbe 4, Udine \\ 33100, Italy. Tel: + 432 494382; Fax: + 432 494301; \\ E-mail: cbrancolini@makek.dstb.uniud.it
}

Received 17.5.05; revised 09.6.05; accepted 17.6.05

Edited by G Melino

\begin{abstract}
Several studies have indicated that proteasome inhibitors (PIs) are promising anticancer agents. We have discovered that Pls have the unique ability to activate effector caspases through a mitochondrial Bcl-2 inhibitable but caspase-9 independent pathway. Stabilization of released Smac induced by blockade of the proteasome could explain the apoptosome-independent cell death induced by PIs. Infact, Smac/ DIABLO critically supports this PIs-dependent caspase activation. By using a new assay, we confirm that at a single cell level both Smac and PIs can activate caspases in the absence of the apoptosome. Moreover, we have observed two PIs-induced kinetics of caspase activation, with caspase-9 being still required for the rapid caspase activation in response to mitochondrial depolarization, but dispensable for the slow DEVDase activation. In summary, our data indicate that PIs can activate downstream caspases at least in part through Smac/DIABLO stabilization.

Cell Death and Differentiation (2005) 12, 1240-1254.

doi:10.1038/sj.cdd.4401729
\end{abstract}

Keywords: Caspase; mitochondria; chemotherapy; time lapse; IAP; TMRM; GFP

Abbreviations: Pls, proteasome inhibitors; IAPs, Inhibitor of Apoptosis; TSA, trichostatin A; MEFs, murine embryonic fibroblasts; GFP, green fluorescent protein

\section{Introduction}

Most chemotherapeutic molecules trigger tumor eradication and patient survival by inducing apoptotic cell death. ${ }^{1}$ As a consequence, chemoresistance and tumor progression often arise when cancer cells accumulate mutations in the critical genes regulating the apoptotic program. ${ }^{2}$
Caspases play important roles in the regulation of the apoptotic program. ${ }^{3}$ These proteolytic enzymes, synthesized as inactive zymogens, are divided into initiators and effectors depending on the timing of activation. Initiator caspases are activated earlier following adaptor-mediated oligomerization whereas effector caspases are activated after cleavage mediated by initiator caspases. ${ }^{4,5}$ Once activated effector caspases process selected death substrates and other caspases in an amplificatory loop that causes cell fragmentation. ${ }^{6}$

The mitochondrial or intrinsic pathway of caspase activation represents the fundamental switch in the apoptotic response triggered by different cellular stresses. ${ }^{7}$ Anti and proapoptotic Bcl-2 family members are the guardians of mitochondrial integrity. They work in an antagonized manner to control outer mitochondrial membrane permeability and the release of mitochondrial proapoptotic factors into the cytosol. ${ }^{8,9}$ Cytochrome $c$ was the first identified proapoptotic factor released from the mitochondria into the cytosol, where it stimulates the formation of the apoptosome, an oligomeric complex containing the adaptor protein Apaf-1 and the initiator caspase-9. ${ }^{7}$

Smac/DIABLO and HtrA2/Omi, similar to cytochrome $c$, are released from mitochondria during apoptosis. Their principal function is to relieve the inhibition imposed by inhibitor of apoptosis (IAPs) on caspase-9, -3 and -7 . The synergistic action of cytochrome $c$, Smac/DIABLO and HtrA2/Omi leads to full activation of caspases and cell death. ${ }^{7,10}$

Signals activated by many chemotherapeutic molecules converge on caspase- 9 and the apoptosome after triggering mitochondrial permeabilization. ${ }^{11}$ The central role of the apoptosome in apoptosis induced by different anti-tumor treatments has been clearly established by a large body of data. ${ }^{12-17}$

To identify molecules that can trigger cell death bypassing the apoptosome dependence, we screened a number of chemical principles, including many chemotherapeutic molecules, for their ability to triggering apoptosis in human cells engineered to express a dominant negative form of caspase9. Here, we report the identification of proteasome inhibitors (PIs) as the only molecule able to induce efficient caspase activation and cell death even in the absence of a functional apoptosome. We also provide evidence that Smac/DIABLO plays a role in the caspase- 9 independent apoptotic pathway activated by PIs.

\section{Results}

\section{Pls trigger caspase activation and cell death independently from caspase-9}

To identify compounds able to induce efficient caspase activation and apoptosis in tumor cells independently from the apoptosome, we took advantage of IMR90-E1A human cells, engineered to express a dominant-negative form of caspase-9. ${ }^{13}$ IMR90-E1A (E1A) and IMR90-E1A/C9DN (E1A/ 
C9DN) cells were treated with different chemical principles provided of anti-cancer activity represented in Figure 1a. The list of anticancer compounds includes antitubulin drugs, nucleoside analogs, topoisomerases inhibitors, anthracycline antibiotics and DNA cross-linking agents. We integrated our list with more recently characterized antineoplastic activities such as PIs, histone deacetylase inhibitors and ether lipids, by using, respectively, ALLnL ( $N$-Acetyl-Leu-Leu- $N$-Leu-CHO), trichostatin $\mathrm{A}$ (TSA) and $\mathrm{ET}-18-\mathrm{OCH}_{3}$ as prototype molecules.

E1A and E1A/C9DN cells were treated with the different compounds and caspase- 3 and -7 activities were measured 24-48 $\mathrm{h}$ later using a fluorogenic peptide substrate. The ability to trigger caspase activation independently from caspase- 9 was represented as the ratio of caspase-3/-7 activity in $E 1 A$ / C9DN versus E1A cells (Figure 1a). ALLnL was able to trigger caspase activity at similar levels in both cell lines whereas all the other tested drugs showed a certain degree of dependence from caspase-9. The ability of ALLnL to trigger full DEVDase activity in cells lacking a functional caspase- 9 was confirmed in four different experiments (Figure 1b). TSA was used as negative control since it has been demonstrated to be a strictly caspase- 9 dependent apoptotic stimulus. ${ }^{18}$

To demonstrate that the ability of ALLnL to trigger apoptosis and caspase activation in a caspase- 9 independent manner was due to proteasome inhibition and not due to the inhibition of calpains and cathepsins, ${ }^{19,20} \mathrm{E} 1 \mathrm{~A}$ and E1A/C9DN cells were treated with two more specific PIs such as MG-132 (ZLeu-Leu-Leu-CHO) and PSI (Z-Ile-GIn(OtBu)-Ala-Leu-CHO). We also used the specific calpain inhibitor ALLM ( $N$-acetylLeu-Leu-Met-CHO) that does not inhibit the proteasome. Etoposide, a typical caspase- 9 dependent drug, was used as a control.

All the PIs tested induced cell death at similar levels in both cell lines. The calpain inhibitor was ineffective in inducing cell death whereas etoposide, as expected, was less efficient in triggering apoptosis in E1A/C9DN cells (Figure 1c). Next, we evaluated the proteolytic processing of caspases and of caspase substrates in E1A/C9DN cells treated with PIs compared to etoposide. E1A and E1A/C9DN cells were incubated with ALLnL, MG-132, or etoposide at doses that had been previously tested to trigger comparable apoptosis in E1A cells (Figure 1c). Accordingly, immunoblots showed similar amounts of processed caspase-2 and -8 after treatment with Pls and etoposide in E1A cells. Comparable processing was also observed for the death substrate PARP. In E1A/C9DN cells apoptosis and processing of caspase-2, -8 and PARP were lower after treatment with etoposide, whereas they were similar after treatment with PIs when compared to E1A cells. ALLM was unable to trigger caspase2, -8 and PARP processing in neither of the cell lines.

A time-course analysis was next performed to evaluate the kinetics of caspase-2, -7, -8 and PARP processing in response to ALLnL (Figure 1e). Cell death, scored by Trypanblue staining, was induced with similar kinetics in $\mathrm{E} 1 \mathrm{~A}$ and E1A/C9DN cells, and also cleavage of caspase-2, -7, -8 and PARP showed a similar schedule.

To confirm the ability of the Pls to overcome the apoptosome, we took advantage of MCF-7/C9DN, which are defective for caspase- 3 and express the dominant negative form of caspase-9. Here again ALLnL and lactacystin but not ALLM induced apoptosis and caspase activation at comparable levels in MCF-7/C9DN and in the control MCF-7/NEO cells (data not shown). To further confirm that PIs trigger caspase activation and apoptosis in the absence of caspase9, Myc-transformed caspase- $9^{+/-}$murine embryonic fibroblasts (MEFs) and caspase- $9^{-1-}$ MEFs were treated with MG-132 or etoposide as a control. MG-132 induced cell death at similar levels in both cell lines whereas etoposide, as expected triggered apoptosis less efficiently in Mycexpressing caspase $-9^{-/-}$MEFs (Figure 1f). In conclusion we have demonstrated that PIs overcome the lack of caspase9 to trigger caspase activation and apoptosis.

\section{Bcl-2 family members control Pls-mediated cytochrome $c$ release and apoptosis}

To understand the mechanisms responsible for the apoptosome-independent caspase activation induced by PIs, we took advantage of BJ cells transformed with E1A, Ras and expressing Bcl-2. Parental E1A/Ras cells efficiently entered apoptosis following ALLnL treatment, while the expression of Bcl-2 dramatically suppressed this apoptotic response as revealed by the Trypan blue assay (Figure 2a). We also characterized the pattern and timing of caspase activation in $\mathrm{E} 1 \mathrm{~A} / \mathrm{Ras}$ cells compared to E1A/Ras/Bcl-2 cells. Processing of caspase-2, $-3,-7,-8$ and that of the death substrate PARP was clearly reduced by the presence of Bcl-2 (Figure $2 b$ ).

Increasing evidences support the idea that $\mathrm{Bcl}-2$ can regulate apoptosis also independently of the apoptosome. ${ }^{21-23}$ Our data on the different effects of Bcl-2 and C9DN in counteracting apoptosis induced by PIs sustain this hypothesis. To further corroborate our observation, we sought to analyze the Pls-induced apoptotic response of E1A and E1A/C9DN cells stably expressing Bcl-2. The trypan blue assays (Figure 2c) showed that apoptosis induced by ALLnL was efficiently counteracted by Bcl-2 independently from the presence of C9DN. TSA was used as a control of the apoptosome inhibition by C9DN. Processing of caspase-2, -7, -8 and of the death substrate PARP was dramatically reduced in $\mathrm{E} 1 \mathrm{~A}$ cells expressing Bcl-2 according to the suppression of the apoptotic response (data not shown).

Recent evidences indicate that the ability of $\mathrm{Bcl}-2$ to prevent cell death independently of Apaf- 1 or caspase- 9 is consistent with its ability to prevent cytochrome $c$ release from mitochondria. $^{21}$ Thus, we evaluated the release of cytochrome $c$ from mitochondria in E1A, E1A/Bcl-2, E1A/C9DN and $\mathrm{E} 1 \mathrm{~A} / \mathrm{C} 9 \mathrm{DN} / \mathrm{Bcl}-2$ cells by immunofluorescence after treatment for $12 \mathrm{~h}$ with $\mathrm{ALLnL}$. As shown in Figure 2d, cytochrome $c$ release from mitochondria was reduced in cells expressing Bcl-2. Similar results in terms of apoptotic suppression and cytochrome $c$ release were obtained when $\mathrm{Bcl}-\mathrm{xL}$, instead of Bcl-2, was ectopically expressed (data not shown).

Genetic evidences indicate that the multidomain proapoptotic proteins Bax and Bak are required for the response to many apoptotic stimuli. ${ }^{24}$ To unveil the role of these proteins during Pls-dependent apoptosis, immortalized wild-type MEFs and $b a x^{-1-} b a k^{-1-}$ MEFs were treated with ALLnL. We found that the absence of Bax and Bak expression 
dramatically reduced the apoptotic response to ALLnL compared to wild-type MEFs (Figure 2e). Accordingly, caspase-3/-7 activities and caspase- 2 and $\beta$-catenin processing were almost completely suppressed in $\mathrm{bax}^{-/-} \mathrm{bak}^{-/-}$
MEFs challenged with ALLnL (Figure 2f and g). Overall our experiments indicate that the Bcl-2 family members control alternative mitochondrial pathways of caspase activation that overcome caspase-9. a

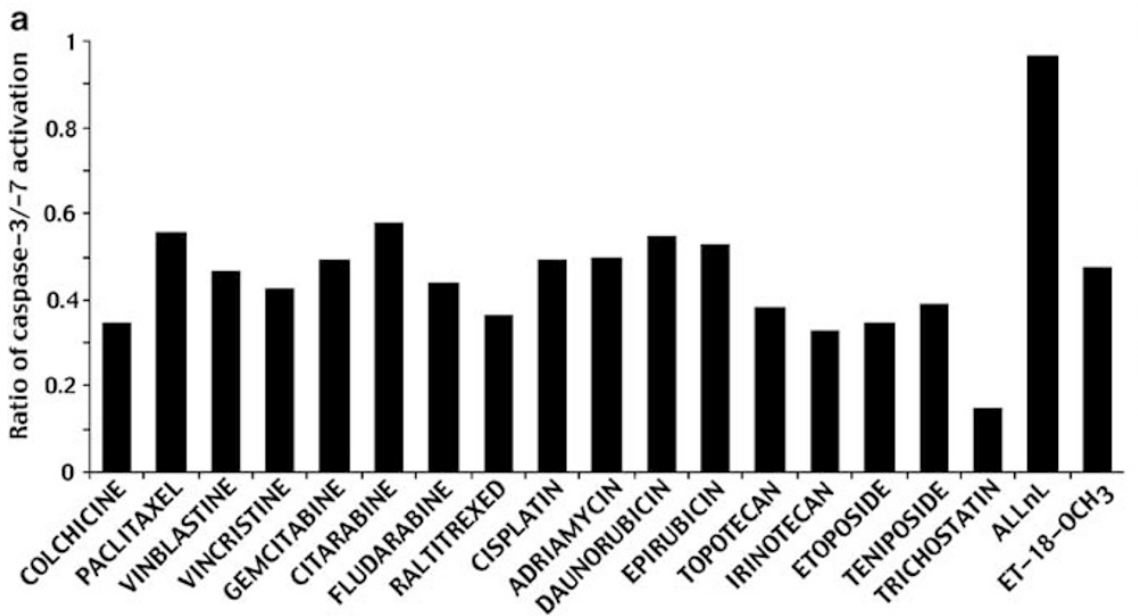

b

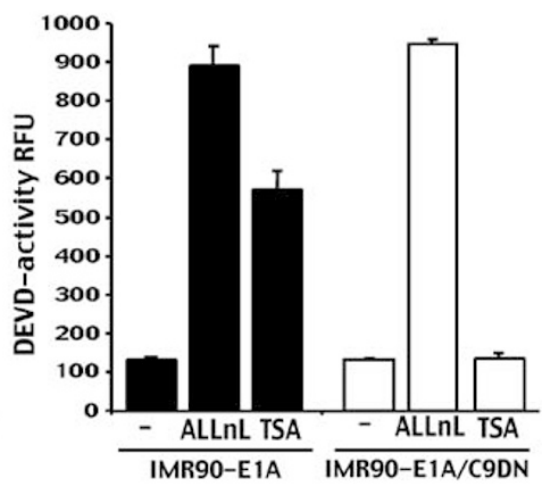

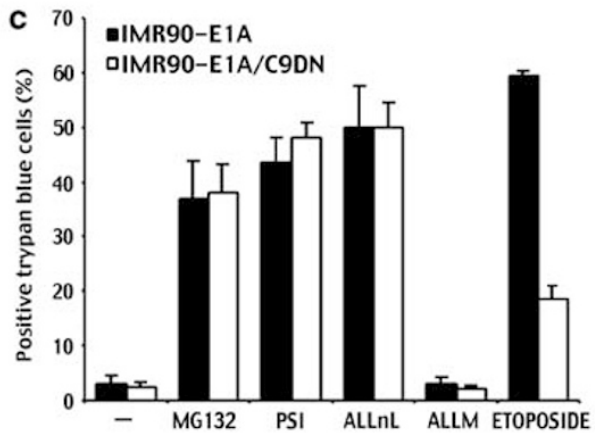
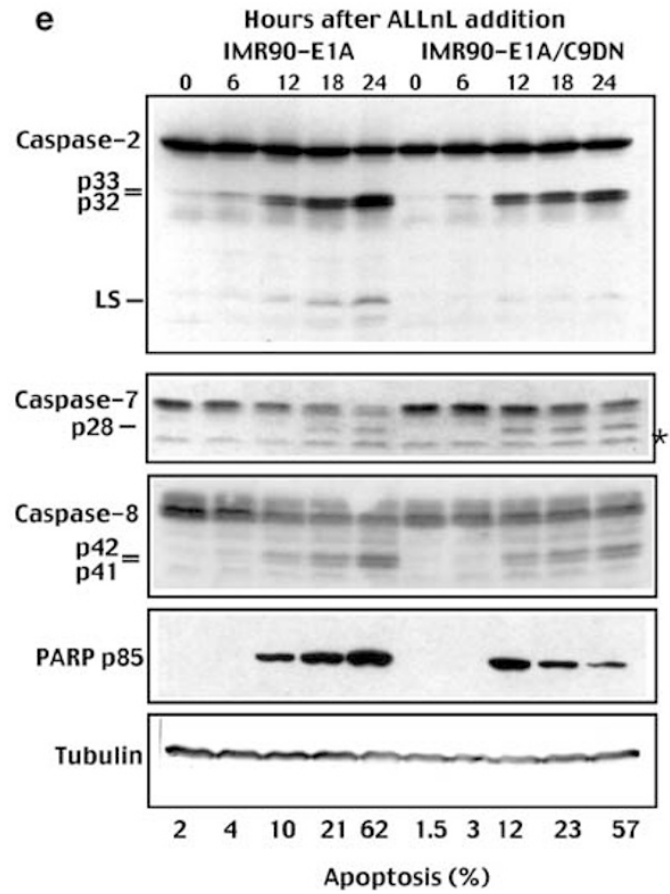
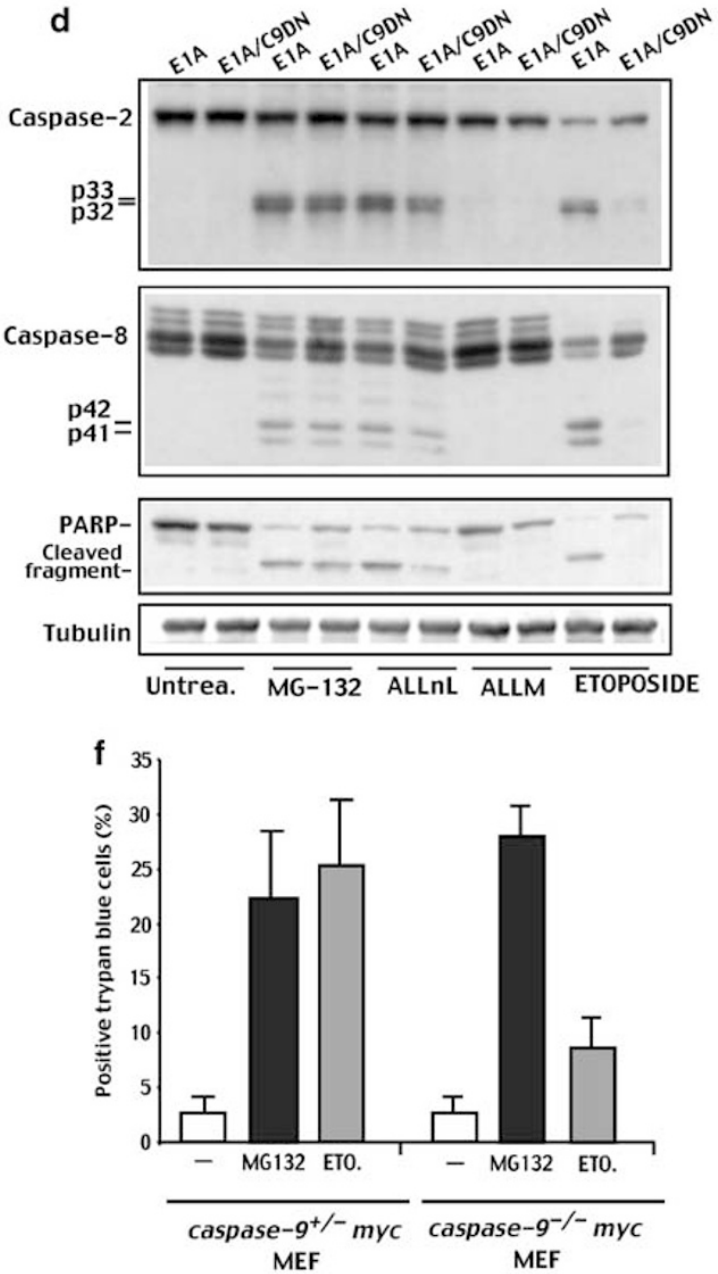


\section{Analysis of caspase activation at the mitochondria surface of a single cell in vivo}

Recent studies indicate that caspase- 9 and the apoptosome have an important role in accelerating rather than in dictating cell death. ${ }^{21,22}$ Therefore, it is possible that, even though PIs can trigger caspase activation in the absence of caspase- 9 , the kinetic of activation may be affected by the absence of the accelerating function of the apoptosome. Therefore, we decided to study in detail the timing of caspase activation in C9DN cells after treatment with Pls.

Since apoptosis is an asynchronous process, the timing of caspase activation needs to be analyzed in single cells. Our results suggest that mitochondria play a critical role during the apoptotic response triggered by PIs. Mitochondrial membrane potential $\left(\Delta \psi_{\mathrm{m}}\right)$ is often employed as an indicator of cellular viability and its destruction has been implicated in many apoptotic responses. ${ }^{25,26}$ Single-cell imaging studies have shown that $\Delta \psi_{\mathrm{m}}$ decrease is concomitant to the release of cytochrome- $c^{27}$ and that its rapid loss requires caspase activity. ${ }^{28}$ Therefore, in order to examine the timing of caspase activation during apoptosis induced by Pls it is important to monitor simultaneously $\Delta \psi_{\mathrm{m}}$ and caspase activation possibly close to mitochondria. For this purpose, we have developed a new assay to monitor, simultaneously, $\Delta \psi_{\mathrm{m}}$ and caspase activity on the outer mitochondria membrane (OMM) of single cells.

We generated a set of hybrid proteins containing a green fluorescent protein (GFP), one (D or AD) two (DD) or no (AA) effector caspases consensus cleavage sites and the transmembrane domain of $\mathrm{Bcl}-\mathrm{xL}$ (TM), which is needed to target the fusion protein to the OMM (Figure 3a). GFP translocates from the OMM to the cytoplasm only after effector caspases cleave the DD sites allowing us to measure caspase activity in a single cell in vivo (Figure $3 \mathrm{c}$ and d).

Despite the fact that all the different chimeric proteins localize to the mitochondria (Figure $3 b$ ), their cleavage efficiency, following apoptosis induced by etoposide, was different depending on the presence of one or two caspase cleavage sites. As shown in Figure 3c, GF-DD-TM was fully processed in the apoptotic population whereas GFP-AD-TM and GFP-D-TM were only partially processed. As expected GFP-AA-TM was not processed. In all the different experiments apoptosis was similarly induced, as confirmed by PARP processing. These cleavages were inhibited by the addition of the caspase inhibitor Boc-D-fmk (Figure $3 \mathrm{e}$ ) and the expression of these constructs did not affect cell growth or the apoptotic process (Figure 3f).

The GFP-DD-TM and the control GFP-AA-TM chimeras were chosen for the following studies. E1A cells were microinjected with the two different constructs and exposed to etoposide. Subcellular localization of the two chimeras and mitochondrial depolarization, measured by the decrease in tetramethyl rhodamine methyl-ester (TMRM) uptake,${ }^{29}$ were simultaneously analyzed by time-lapse confocal microscopy. GFP was completely released into the cytosol in a short frame of time only in cells expressing GFP-DD-TM. In cells expressing the uncleavable mutant GFP-AA-TM, the GFP was confined to the OMM even during the late phase of the apoptotic process (Figure $3 d$ ).

Our results indicate that the generated GFP chimeras can be used to monitor caspase activity in single living cells by time-lapse analysis.

\section{$\Delta \psi_{\mathrm{m}}$ dissipation and caspase activation during etoposide or PIs-induced apoptosis}

To investigate the relationships between caspase activation and mitochondrial depolarization in response to etoposide or MG-132 (used as a prototype of PIs for the succeeding analysis, but similar data were obtained with ALLnL), we analyzed the redistribution of GFP into the cytosol by measuring the decrease in the standard deviation (S.D.) from the average pixel intensity. The S.D. was higher in conditions of mitochondrial GFP localization whereas it was lower during diffuse fluorescence (activated effector caspases). $\Delta \psi_{\mathrm{m}}$ dissipation was analyzed by measuring the changes in total TMRM fluorescence of mitochondria by determining the integrated intensity. Since individual cells depolarize and release GFP from mitochondria at different times from the addition of the proapoptotic insult, the beginning of depolarization (TMRM decrease) was set to min zero. Figure 4a shows that TMRM decrease and GFP translocation were heterogeneous in cells treated with etoposide. In general, cells showing a slower depolarization also exhibited delayed caspase activation (compare the green and violet traces in Figure 4a). In contrast, the kinetic of GFP translocation was rapid $(6.76 \pm 0.57 \mathrm{~min}, n=17)$ and comparable in the different cells indicating that, once caspases are activated, the chimeric protein is efficiently and rapidly cleaved in all the cells analyzed.

Compared to etoposide, MG-132 induced faster and more homogeneous $\Delta \psi_{\mathrm{m}}$ dissipation with many cells reaching the bottom level after $60 \mathrm{~min}$ (Figure 4b). As for etoposide the kinetics of GFP translocation induced by MG-132 were rapid $(9.57 \pm 1.31 \mathrm{~min}, n=14)$ and similar in the different cells analyzed (Figure 4b).

Of note, in etoposide treated cells the interval between full caspase activity and the beginning of mitochondrial de-

Figure 1 Proteasome inhibitors induce caspase activation and apoptosis in cells expressing a dominant-negative form of caspase-9. (a) E1A and E1A/C9DN cells were treated with the indicated drugs and caspase-3/-7 activities have been measured with Ac-DEVD-AMC (7-amino-4-methyl-coumarin) fluorogenic substrate. Data are reported as the ratio of DEVDase activity between E1A/C9DN and E1A cells. (b) DEVDase activity in E1A and E1A/C9DN cells treated with ALLnL or TSA as indicated (means \pm S.D.; $n=4$ ). Results show the average of four independent experiments. (c) E1A and E1A/C9DN cells were treated with the indicated apoptotic stimuli and the appearance of apoptosis was scored by Trypan blue staining (means + S.D.; $n=3$ ). (d) Processing of caspase-2, -8 and PARP in E1A and E1A/C9DN cells treated with PIs, ALLM or etoposide. Equal amounts of cell lysates were subjected to SDS/PAGE electrophoresis. Immunoblots were performed using the indicated antibodies. Tubulin was used as loading control. (e) Processing of caspase-2, -7 -8 and PARP in E1A and E1A/C9DN cells treated with ALLnL for the indicated time. Equal amounts of cell lysates were subjected to SDS/PAGE electrophoresis. Immunoblots were performed using the indicated antibodies. The appearance of apoptosis was scored by Trypan blue staining. (f) MEFs from caspase $-9^{-1+}$ or $-9^{-1-}$ mice expressing c-myc were either treated or not treated for $24 \mathrm{~h}$ with etoposide or MG-132. The appearance of apoptosis was scored by Trypan blue staining (means \pm S.D.; $n=3$ ) 
polarization is shorter $(10.24 \pm 3.34 \mathrm{~min}, n=17)$ than in MG-132 treated cells $(27.29 \pm 3.75, n=14), P<0.05$. Finally, we verified that GFP translocation into the cytosol was a consequence of caspase activity and not a secondary event caused by OMM rupture. When the time-lapse analysis was performed with the Asp mutant chimera (GFP-AA-TM) we a

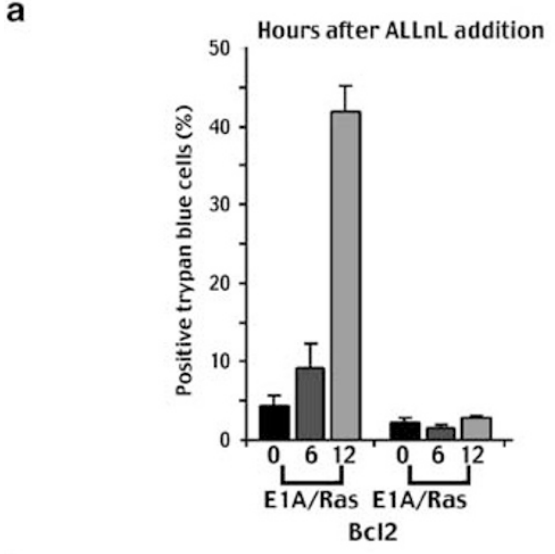

b
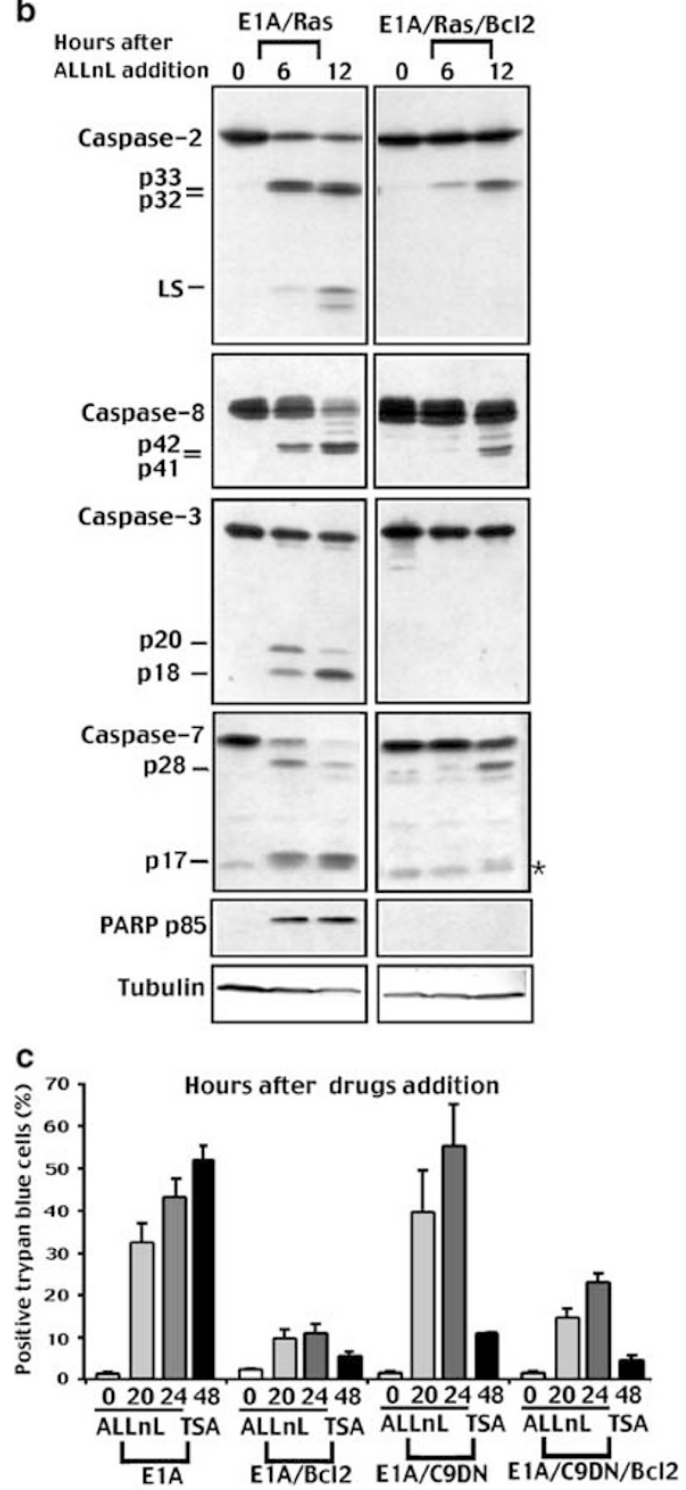

d

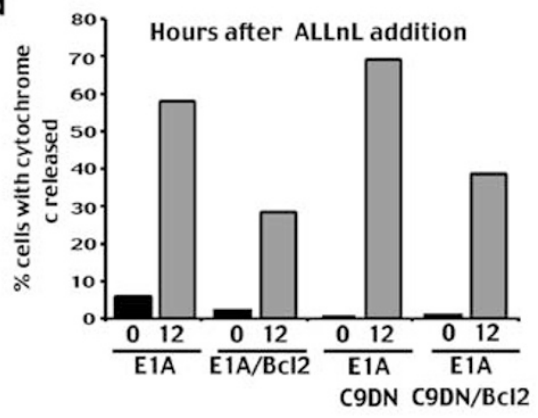

e $\quad 100 \quad$ Hours after drugs addition
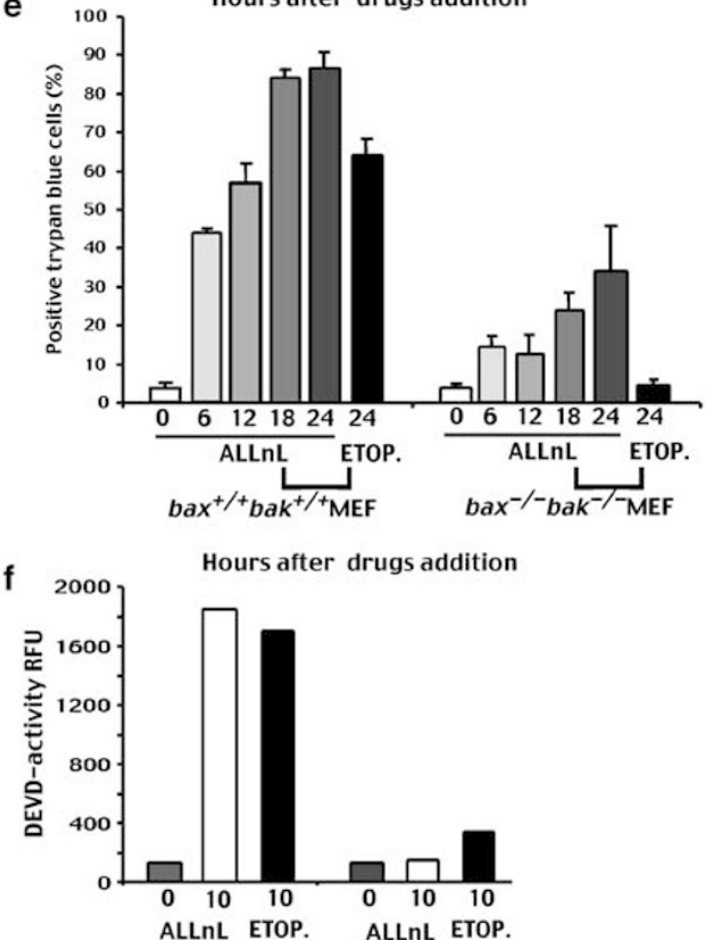
bax $^{+/+}$bak $^{+/+}$MEF bax $^{-/{ }^{-} \text {bak }^{-/ /} \text {MEF }}$
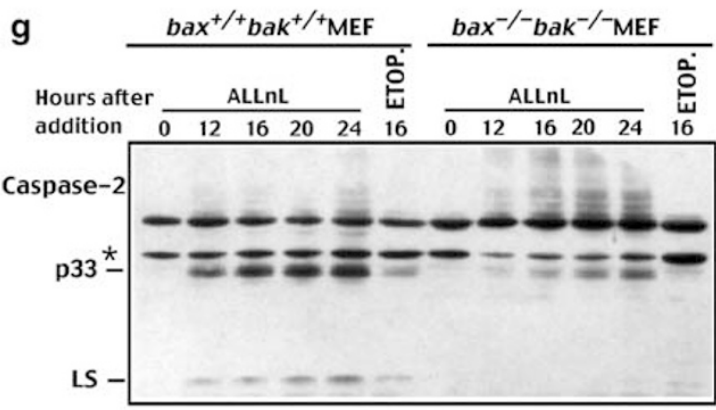

$\beta$-catenin cleavedfragment

Actin 
were unable to observe GFP translocation in the cytosol even after $2 \mathrm{~h}$ from the onset of mitochondrial depolarization (Figure 4c).

\section{$\Delta \psi_{\mathrm{m}}$ dissipation and caspase activation during etoposide or Pls-induced apoptosis in cells defective for caspase-9}

As for E1A cells, we investigated the timing of caspase activation in relation to $\Delta \psi_{\mathrm{m}}$ dissipation in $63 \mathrm{E} 1 \mathrm{~A} / \mathrm{C} 9 \mathrm{DN}$ cells after treatment with MG-132 or etoposide. Etoposide-induced $\Delta \psi_{\mathrm{m}}$ loss was much slower in E1A/C9DN cells than in $\mathrm{E} 1 \mathrm{~A}$ cells. A new steady-state level is reached and maintained through the time $\left(\Delta \psi_{\text {m-caspase-9 }}\right)$ as shown previously in z-VAD-fmk-treated cells. ${ }^{30-32}$ This new steady-state level was about $40-60 \%$ of the initial $\Delta \psi_{\mathrm{m}}$ and it was detectable even after $240 \mathrm{~min}$ from the onset of depolarization (Figure 4d). In etoposide-treated E1A/C9DN cells, GFP remained on the OMM suggesting that caspase activity was dramatically reduced (Figure $4 d$ ). When the same analysis was performed with MG-132, we observed that the dissipation of $\Delta \psi_{\mathrm{m}}$ in E1A/C9DN cells was almost indistinguishable from the one observed in MG-132 treated E1A cells (compare Figure $4 \mathrm{~b}$ and e). As expected, GFP was efficiently translocated to the cytoplasm confirming the ability of PIs to sustain caspase activation in the absence of a functional apoptosome. However, the time-lapse analysis demonstrates that the time span between the onset of depolarization and full caspase activation was delayed by approximately $120 \mathrm{~min}$ in MG-132-treated E1A/C9DN cells $(146 \pm 16 \mathrm{~min}, n=16)$ compared to E1A cells $(27.29 \pm 3.75$ $n=14) P<0,05$.

In summary, $\mathrm{Pls}$ can trigger effector caspases activation in the absence of caspase- 9 , but an increased period of time is required to observe full caspase activation from the onset of $\Delta \psi_{\mathrm{m}}$ decrease.

\section{Biologically active cytosolic Smac/DIABLO can synergize with etoposide to induce efficient apoptosis and caspase activation in cells defective for caspase-9}

Some reports suggest that the levels of cytosolic-released Smac/DIABLO, which acts by relieving the inhibitory action of IAPs on caspases, ${ }^{10}$ could be controlled by the proteasome. ${ }^{33,34}$ The IAPs can promote Smac/DIABLO ubiquitination and degradation in vitro. ${ }^{33-38}$ To shed light on the role of Smac/DIABLO in the apoptosome-independent activation of the effector caspases, we first examined whether we could restore etoposide sensitivity, in terms of efficient caspase activation and apoptosis, in E1A/C9DN cells by increasing the levels of cytosolic Smac/DIABLO. We took advantage of the ubiquitin-Smac/DIABLO fusion system ${ }^{39}$ to obtain the mature Smac/DIABLO protein in the cytoplasm beginning with the AVPI sequence $(\Delta 53)$. We also used the deletion $\Delta 57$, initiating with the sequence AQKS, which is still able to bind the IAPs and to induce some caspase activation, albeit with lower efficiency compared to $\Delta 53 .{ }^{40-43}$ Furthermore, we generated a larger deletion $(\Delta 71)$, which initiates with the MRRA sequence (Figure $5 \mathrm{a}$ ) and fails to bind XIAP and to trigger caspase activation. ${ }^{40}$

The different Smac/DIABLO deletion mutants were cotransfected together with GFP in E1A and E1A/C9DN cells; apoptosis was induced by etoposide and it was scored in vivo by monitoring the appearance of membrane blebbing in green cells. While overexpression of the different deletion mutants did not significantly modify the apoptotic response in $\mathrm{E} 1 \mathrm{~A}$ cells (Figure $5 \mathrm{~b}$ ), Smac/DIABLO $\Delta 53$ and $\Delta 57$ significantly lowered the apoptotic threshold of etoposide-treated E1A/C9DN cells, whereas the $\Delta 71$ was ineffective (Figure $5 c$ ).

The role of Smac/DIABLO in caspase-9 independent apoptosis was further supported by the increased caspase-3 cleavage/activation observed in E1A/C9DN cells expressing Smac/DIABLO $\Delta 53$ after treatment with etoposide. In this assay, E1A/C9DN cells were transiently cotransfected with caspase-3 containing the GFP at the carboxy terminus and with Smac/DIABLO $\Delta 53$ or $\Delta 71$. $\beta$-Gal was used as control for transfection efficiency. A low level of caspase-3 activation was observed in E1A/C9DN cells after overexpression of Smac/ DIABLO $\Delta 53$, but it was greatly increased in the presence of etoposide (Figure $5 d$ ). Caspase-3 activation can be scored by comparing the rate between the amount of pro-caspase-3GFP and the amount of the cleaved form (small subunit of caspase-3 fused to GFP). In cells expressing Smac/DIABLO $\Delta 71$ and treated with etoposide only a faint increase in caspase-3 processing can be observed (Figure 5d). MG-132 was able to induce caspase-3 activation even when Smac/ DIABLO $\Delta 71$ was expressed and here again the rate of caspase-3 processing was further increased by the presence of Smac/DIABLO $\Delta 53$. Therefore, high levels of biologically active cytosolic Smac/DIABLO can sensitize apoptosomedeficient cells to drug-induced apoptosis bypassing the requirement of active caspase- 9 .

XIAP can regulate Smac/DIABLO protein levels by acting as E3 ubiquitin ligase..$^{33,36,34,38}$ Ectopic expression of XIAP should efficiently counteract apoptosis induced by PIs. XIAP was able to counteract apoptosis (Figure 5e) and caspase-3

Figure 2 Bcl-2 family members control Pls-mediated cytochrome $c$ release and apoptosis. (a) BJ/E1A/Ras and BJ/E1A/Ras/Bcl-2 cells were treated with $A L L n L$ for the indicated time and the appearance of apoptosis was scored by Trypan blue staining (means \pm S.D.; $n=3$ ). (b) Processing of caspase-2, $-3,-7,8$ and PARP in BJ/E1A/ Ras and BJ/E1A/Ras/Bcl-2 cells treated with ALLnL for the indicated time. Equal amounts of cell lysates were subjected to SDS/PAGE electrophoresis. Immunoblots were performed using the indicated antibodies. (c) E1A and E1A/C9DN cells either expressing or not expressing Bcl-2 were treated for the indicated times with ALLnL or TSA as indicated. The appearance of apoptosis was scored by Trypan blue staining (means + S.D.; $n=3$ ). (d) E1A and E1A/C9DN cells either expressing or not expressing Bcl-2 were treated for the indicated times with ALLnL. After fixation, cells were scored for the accumulation of cytochrome $c$ into the cytosol by immnuofluorescence. (e) MEFs from wt or bak ${ }^{-1} \mathrm{bax}^{-1-}$ mice were treated for the indicated time with ALLnL or for $24 \mathrm{~h}$ with etoposide. The appearance of apoptosis was scored by Trypan blue staining (means \pm S.D.; $n=3$ ). (f) DEVDase activity in MEFs from wt or bak ${ }^{-1-}$ bax ${ }^{-1-}$ mice treated for the indicated time with ALLnL or etoposide (means \pm S.D.; $n=4$ ). (g) Processing of caspase-2 and $\beta$-catenin in MEFs from wt or bak ${ }^{-1-}$ bax $^{-1-}$ mice treated with ALLnL or etoposide for the indicated time. Equal amounts of cell lysates were subjected to SDS/PAGE electrophoresis. Immunoblots were performed using the indicated antibodies 
a
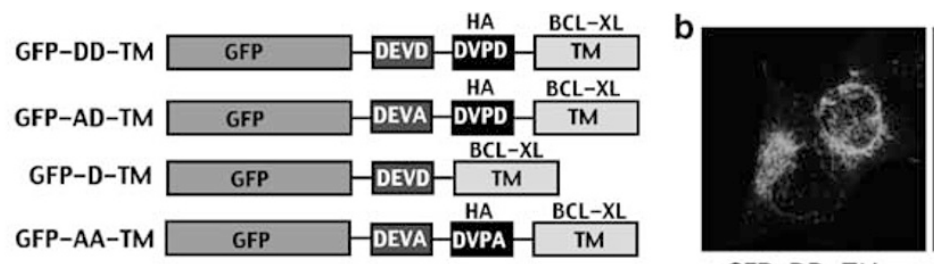

GFP-DD-TM

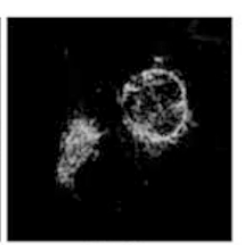

$\alpha$ CytC

C

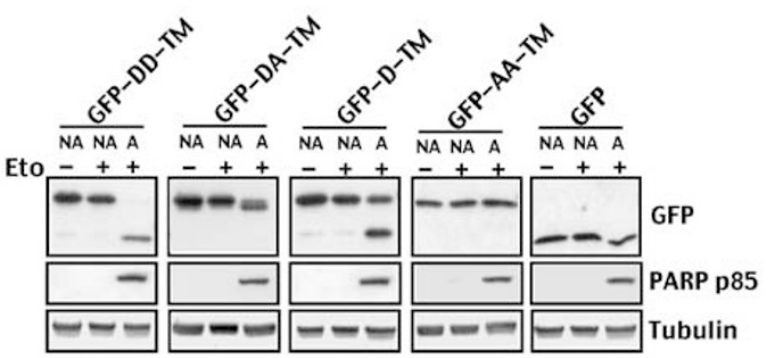

d
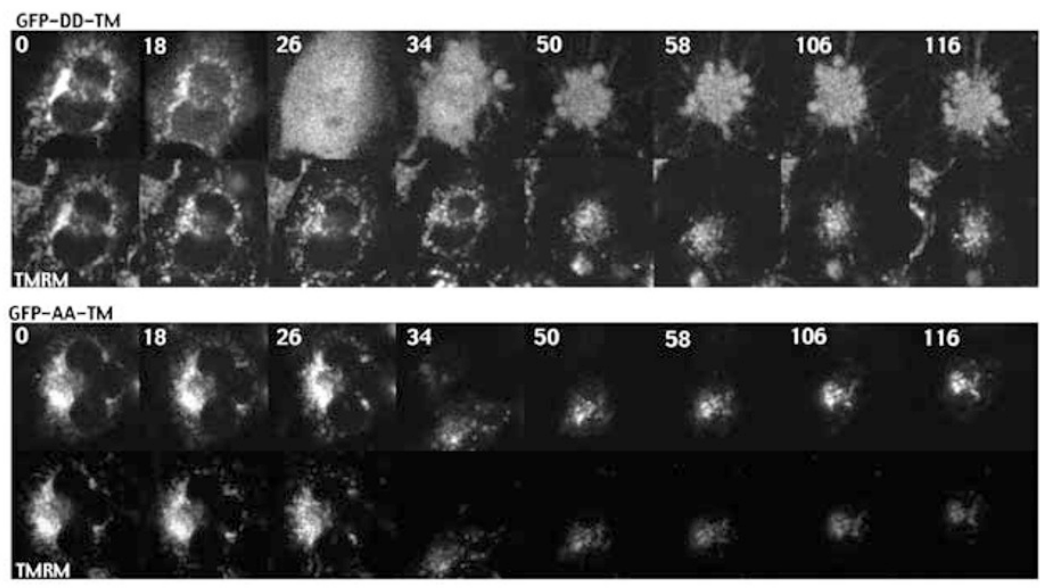

e

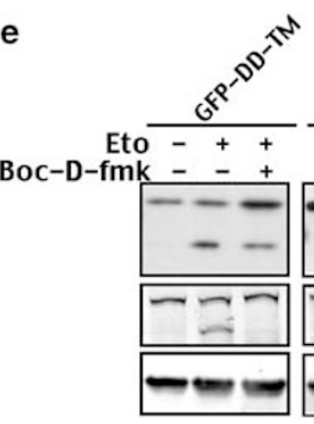<smiles></smiles>

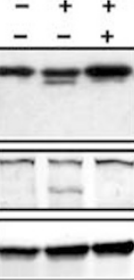<smiles>CC#CC</smiles>

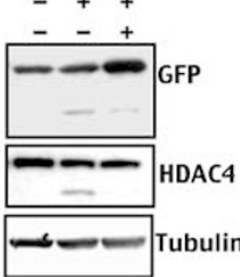

f

\begin{tabular}{rccccccc} 
& \multicolumn{3}{c}{ U20S } & \multicolumn{3}{c}{ U20S } \\
& \multicolumn{3}{c}{ GFP } & \multicolumn{3}{c}{ GFP-DD-TM } \\
\cline { 2 - 8 } Etoposide hrs & 0 & 24 & 48 & & 24 & 48 \\
\cline { 2 - 8 } SubG1 & 2 & 10 & 54 & 1 & 8 & 52 \\
G0/G1 & 56 & 30 & 26 & 50 & 28 & 25 \\
S & 14 & 30 & 9 & 20 & 24 & 10 \\
G2/M & 28 & 30 & 11 & & 29 & 40 & 13 \\
\hline \hline
\end{tabular}

Figure 3 Analysis of caspase activity at a single cell level. (a) Schematic representation of the different GFP chimeras generated. (b) Subcellular localization of the GFP-DD-TM protein in E1A cells. The immunofluorescence assay was performed using the anti-cytochrome $c$ antibody $20 \mathrm{~h}$ after transfection with the GFP-DD-TM plasmid. (c) E1A cells were transfected with the indicated constructs and either treated or not treated with $50 \mu \mathrm{M}$ etoposide for $18 \mathrm{~h}$ as indicated. NA (nonapoptotic) and A (apoptotic) cells were separated and immunoblots were performed using the indicated antibodies. (d) Time-lapse images of E1A cells expressing GFP-DD-TM or GFPAA-TM incubated with etoposide and TMRM. Frames at selected times after the onset of $\Delta \psi_{\mathrm{m}}$ depolarization of a representative cell expressing GFP-DD-TM or GFPAA-TM. (e) E1A cells were transfected with the indicated constructs and either treated or not treated with $50 \mu \mathrm{M}$ etoposide for $18 \mathrm{~h}$, in the presence or not of caspase inhibitor Boc-D-fmk (125 $\mu \mathrm{M})$. Cellular lysates were prepared and immunoblots were performed using the indicated antibodies. (f) Flow cytometric analysis of the cell cycle profile by propidium iodide staining of U2OS cells stably expressing GFP or GFP-DD-TM treated with $50 \mu \mathrm{M}$ etoposide for the indicated time

cleavage (Figure $5 f$ ) induced by the proteasome inhibitor MG-132 with high efficiency in E1A/C9DN and in E1A cells, reinforcing the idea that the IAP antagonist Smac/DIABLO could play an important role in mediating caspase activation in the absence of a functional apoptosome.
Time-lapse analysis with the GFP-DD-TM protein confirmed the ability of Smac/DIABLO to sensitize E1A/C9DN cells to etoposide-induced apoptosis. GFP translocation into the cytosol and complete $\Delta \psi_{\mathrm{m}}$ dissipation can be observed in etoposide-treated E1A/C9DN cells when the levels of 
cytosolic Smac/DIABLO $\Delta 53$ were ectopically increased. Figure $5 \mathrm{~g}$ shows eight representative cells out of 30 analyzed cells (compare with Figure $4 d$ ). Both the timing of caspase activation and the kinetics of depolarization were heterogeneous. Some cells activated caspases after a prolonged time from the onset of depolarization $(192.7 \pm 10.4 \mathrm{~min})$ probably because microinjected cells express different levels of Smac/DIABLO $\Delta 53$.

Overall our data demonstrate that high levels of cytosolic biologically active Smac/DIABLO can sustain caspase activation in the absence of a functional apoptosome.
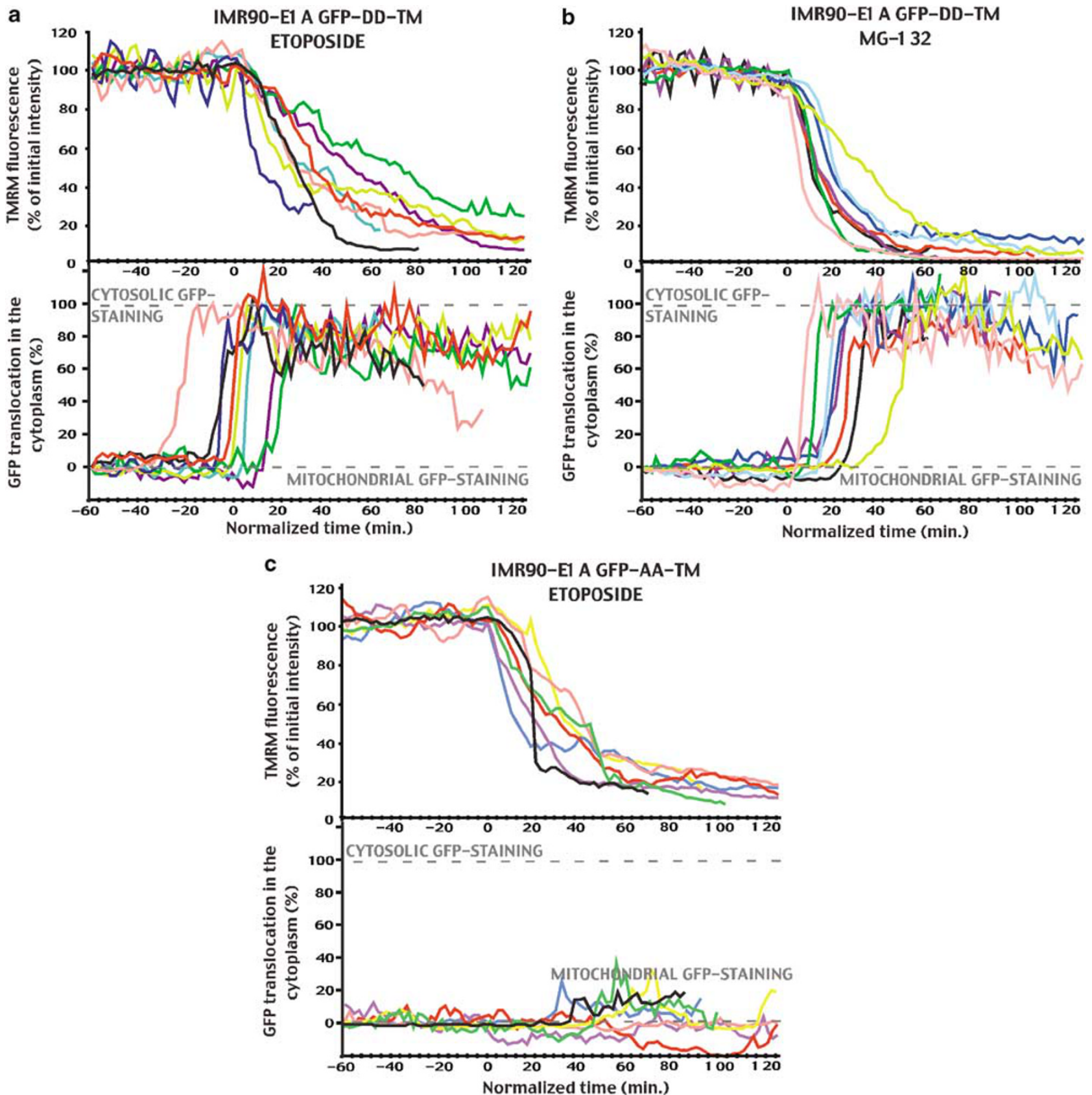

Figure 4 Cytosolic translocation of GFP-DD-TM and decrease of mitochondrial TMRM uptake in single cells as markers respectively of caspase activation and $\Delta \psi_{\mathrm{m}}$ dissipation. (a) Individual traces for TMRM uptake and GFP localization of eight typical E1A cells expressing GFP-DD-TM after treatment with $50 \mu$ M etoposide. In the TMRM and GFP reported traces the same color marks the same cell. (b) Individual traces for TMRM uptake and GFP localization of eight typical E1A cells expressing GFP-DD-TM after treatment with 2,5 $\mu \mathrm{M}$ MG-132. In the TMRM and GFP reported traces, the same color marks the same cell. (c) Individual traces for TMRM uptake and GFP localization of seven typical cells expressing GFP-AA-TM after treatment with $50 \mu \mathrm{M}$ etoposide. In the TMRM and GFP reported traces the same color marks the same cell. (d) Individual traces for TMRM uptake and GFP localization of eight typical E1A/C9DN cells expressing GFP-DD-TM after treatment with $50 \mu$ M etoposide. In the TMRM and GFP reported traces the same color marks the same cell. (e) Individual traces for TMRM uptake and GFP localization of eight typical E1A/C9DN cells expressing GFP-DD-TM after treatment with 2,5 $\mu \mathrm{M}$ MG-132. In the TMRM and GFP reported traces the same color marks the same cell 

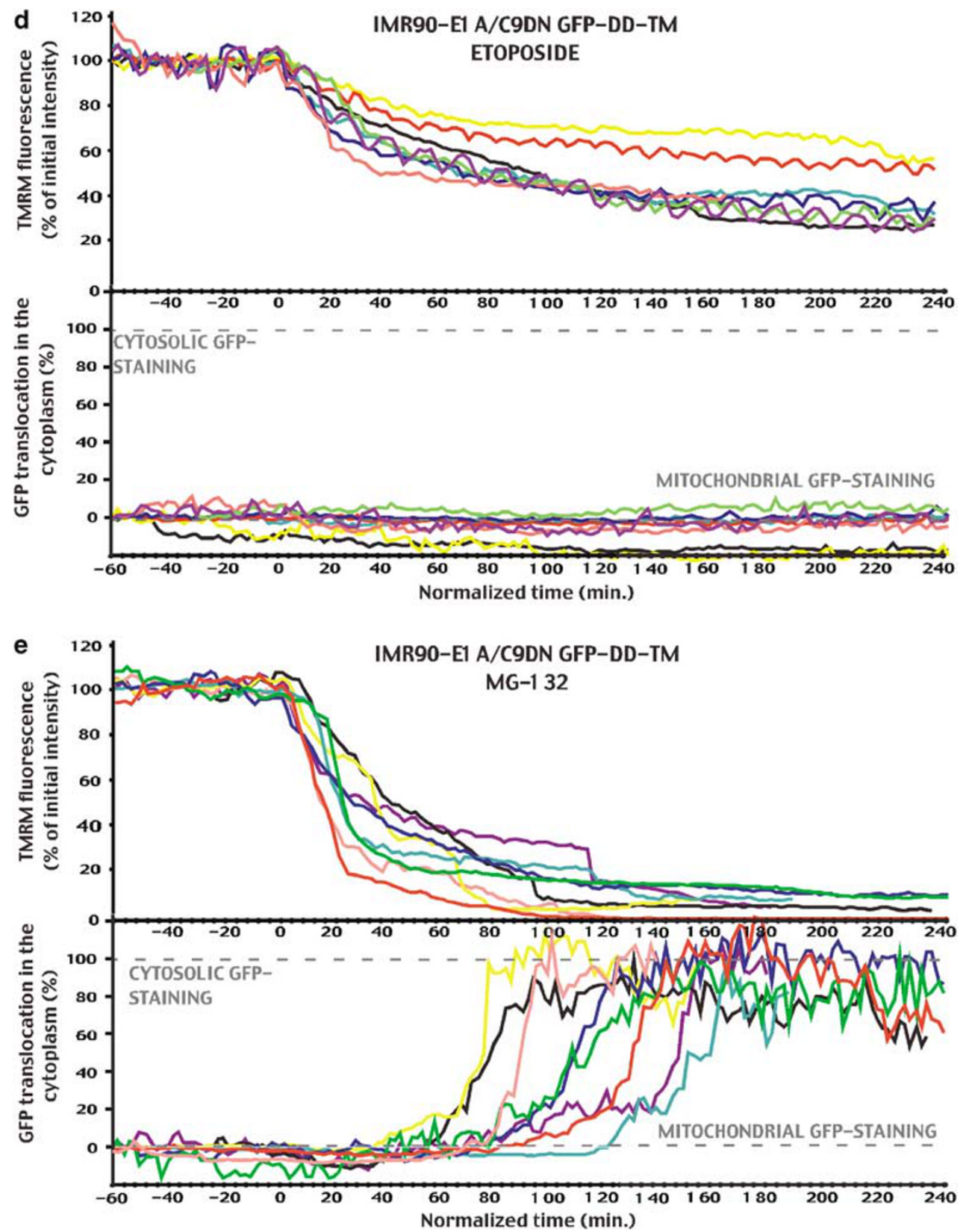

Figure 4 Continued

\section{Endogenous Smac/DIABLO is required for the apoptosome-independent cell death induced by PIs and its level is increased in the cytosol during PIs-induced apoptosis}

We explored the role of endogenous Smac in regulating PIs-dependent caspase activation and apoptosis in E1A/ C9DN cells. Smac expression was downregulated by specific siRNA (Figure 6b) and the apoptotic response to Pls was measured by trypan blue staining and caspase-2 processing. While no effect of Smac siRNA was observed in controluntreated cells, Smac siRNA significantly reduced the susceptibility to apoptosis of E1A/C9DN cells challenged with
MG-132 (Figure 6a). Reduced apoptosis in Smac-depleted cells was confirmed by the reduced proteolytic activation of caspase-2 (Figure 6b).

To support the hypothesis that released Smac is important to sustain apoptosis induced by PIs in caspase-9-defective cells, we investigated whether Pls could regulate the level of endogenous cytosolic Smac once released from mitochondria. Subcellular fractionation was performed to isolate the mitochondrial and cytosolic fractions from $\mathrm{E} 1 \mathrm{~A}$ and $\mathrm{E} 1 \mathrm{~A} /$ C9DN cells after treatment with MG-132 or etoposide at doses that had been previously tested to trigger comparable apoptosis. Trypan blue scoring confirmed that apoptosis was similarly induced in E1A cells by both stimulus (data not 
a

\begin{tabular}{|c|c|c|}
\hline & Ubiquitin & Smac/DIABLO \\
\hline$\Delta 53[$ & & IAVPI \\
\hline$\Delta 57[$ & & TAQKS \\
\hline 171 & & TMRRA \\
\hline
\end{tabular}

d Untr. Etop. MG-132
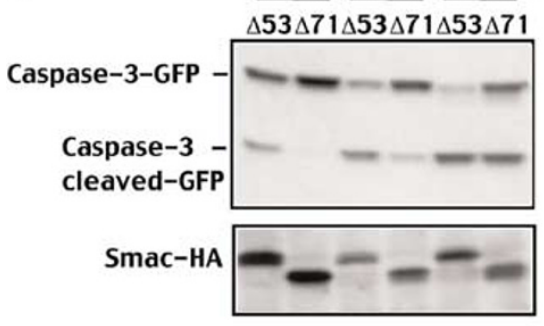

$\beta$-Gal

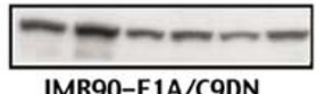

f untr. MG132 Etop.

XIAP

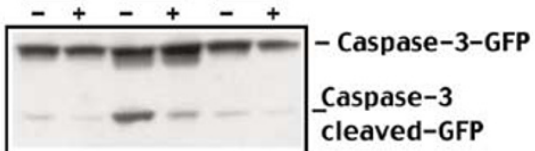

$--\infty-\mathrm{B}-\mathrm{Gal}$

IMR90-E1A/C9DN
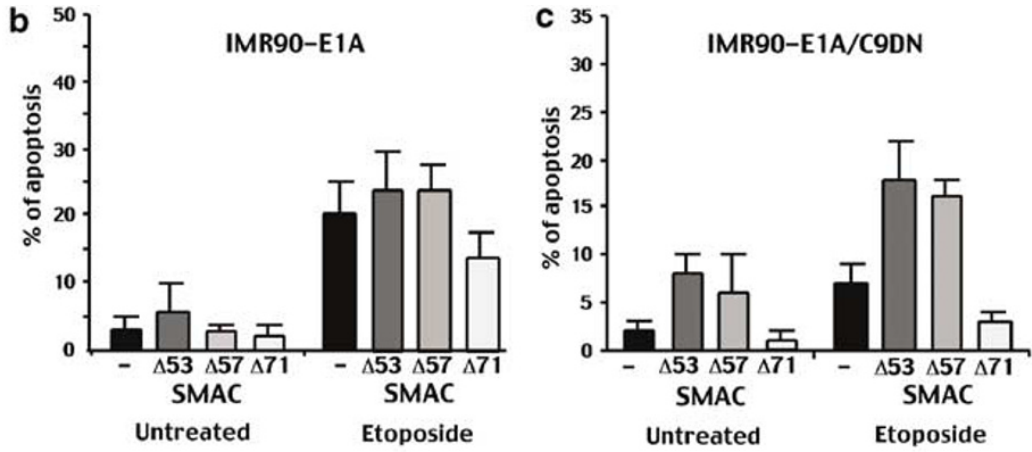

e

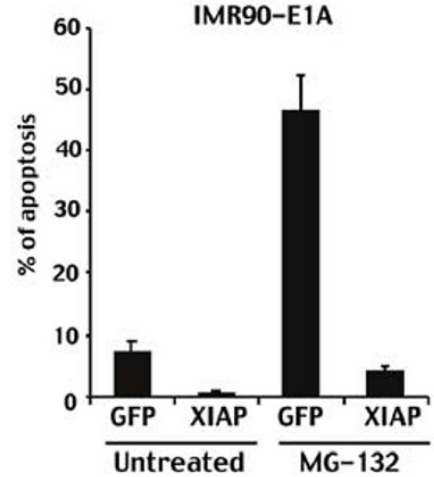

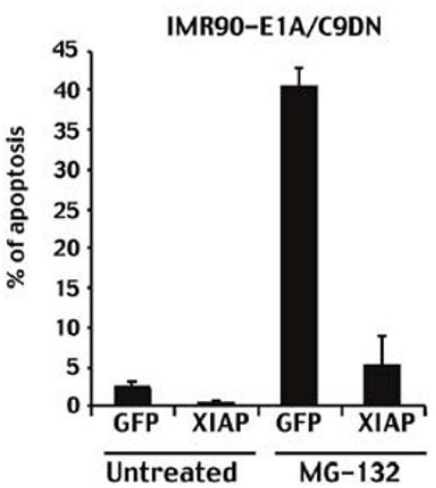

g

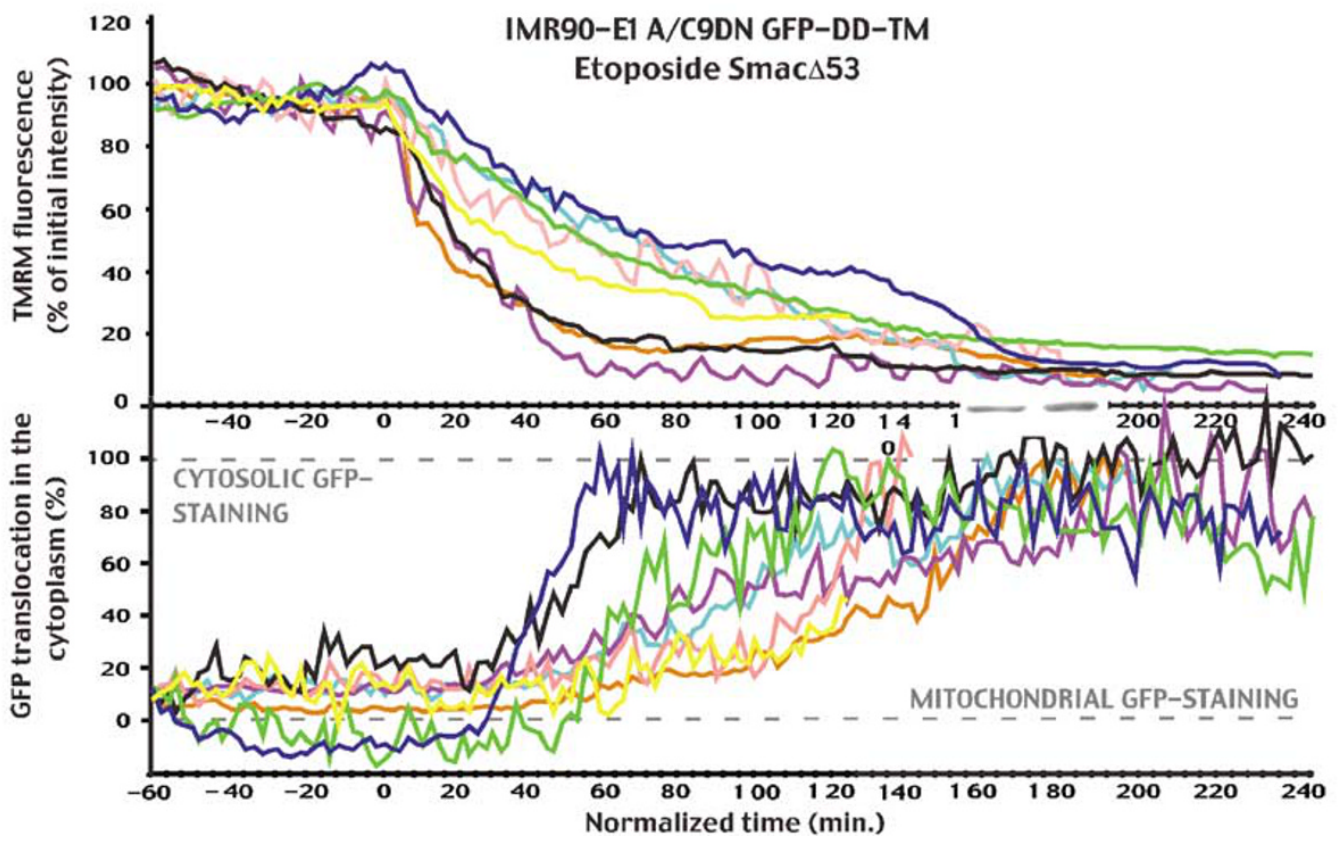

Figure 5 Smac/DIABLO can synergize with etoposide to induce efficient apoptosis and caspase activation in cells containing a caspase-9 dominant negative form. (a) Schematic representation of the different Smac/DIABLO mutants used. (b) The different Smac/DIABLO constructs were transiently expressed in E1A cells together with GFP as reported. Cells were either treated or not treated with etoposide and green cells showing a collapsed morphology and presenting extensive membrane blebbing were scored as apoptotic (means \pm S.D.; $n=6$ ). (c) The different Smac/DIABLO constructs were transiently expressed in E1A/C9DN cells together with GFP as reported. Cells were either treated or not treated with etoposide and cells showing a collapsed morphology and presenting extensive membrane blebbing were scored as apoptotic (means \pm S.D.; $n=6$ ). (d) Caspase-3/GFP Smac $\Delta 53$ or Smac $\Delta 71$ together with $\beta$-galactosidase were transiently expressed in E1A/C9DN cells. After $20 \mathrm{~h}$ of etoposide or MG-132 treatment cell lysates were generated and subjected to Western immunoblotting using the indicated antibodies. (e) XIAP was transiently expressed in E1A or E1A/C9DN cells together with GFP as a reporter. After treatment with MG-132, green cells showing a collapsed morphology and presenting extensive membrane blebbing were scored as apoptotic (means \pm S.D.; $n=6$ ). (f) Caspase-3/GFP XIAP together with $\beta$-galactosidase were transiently expressed in E1A/C9DN cells. After $20 \mathrm{~h}$ of etoposide or MG-132 treatment cell lysates were generated and subjected to Western immunoblotting using the indicated antibodies. (g) Individual traces for TMRM uptake and GFP-DD-TM localization of eight typical E1A/C9DN cells treated with $50 \mu \mathrm{M}$ etoposide and overexpressing Smac/DIABLO $\Delta 53$. In the TMRM and GFP reported traces the same color marks the same cell 

IMR90-E1A/C9DN
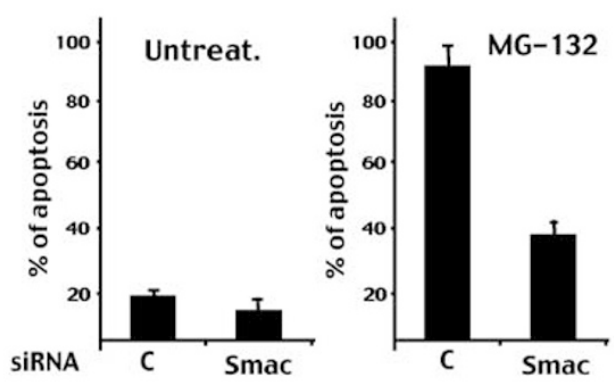

C

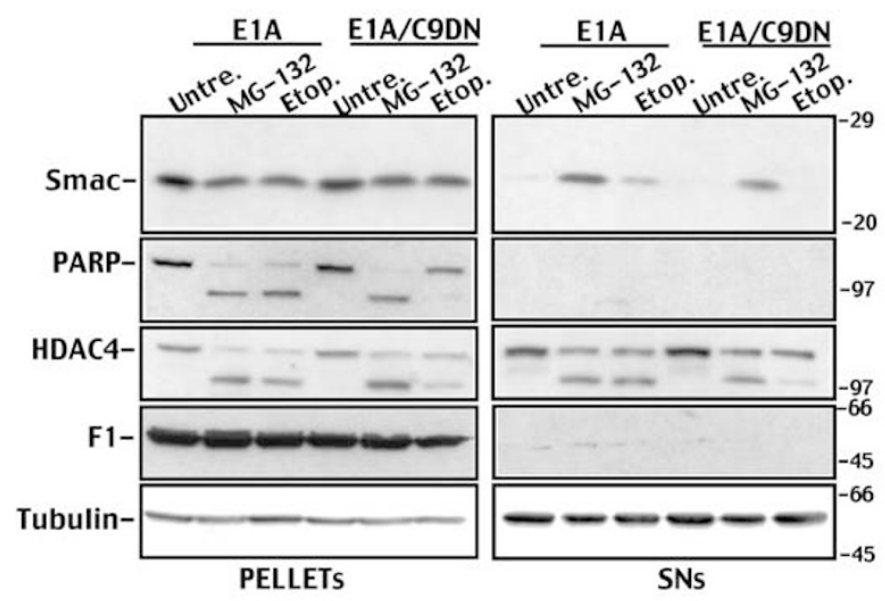

e

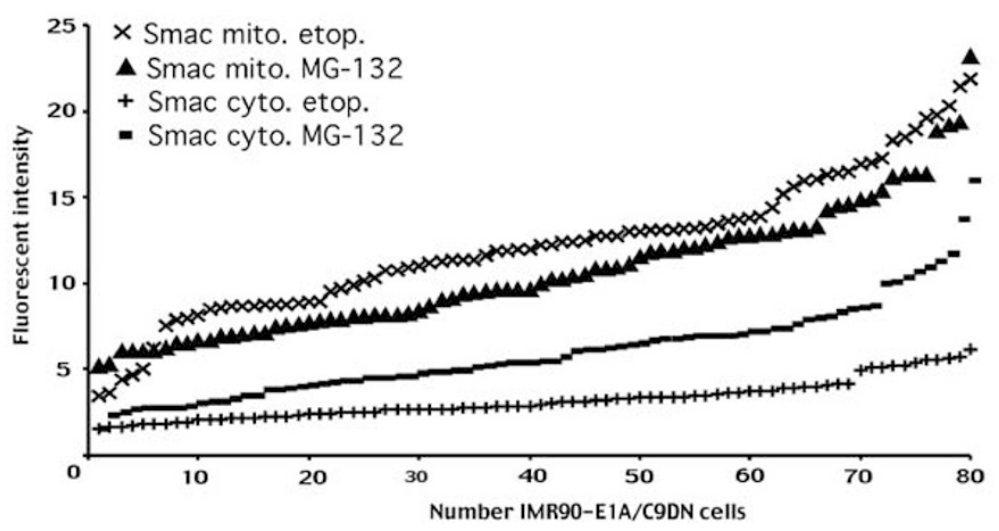

b

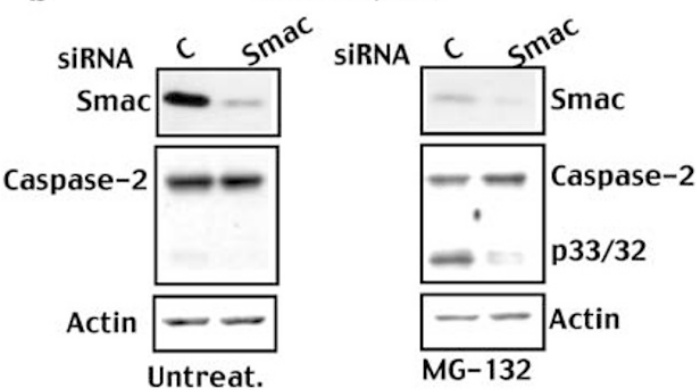

d

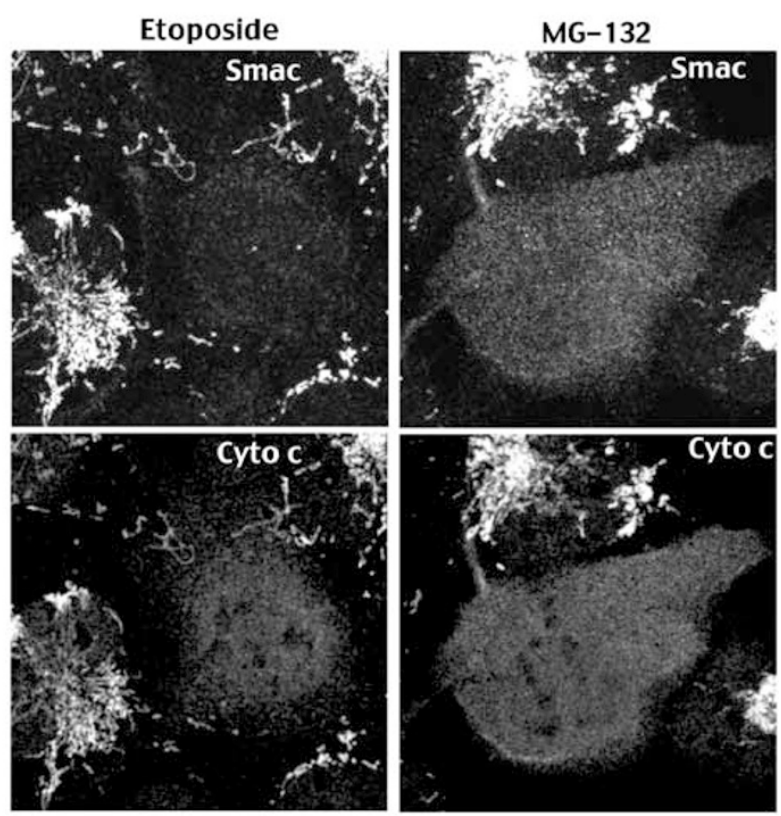

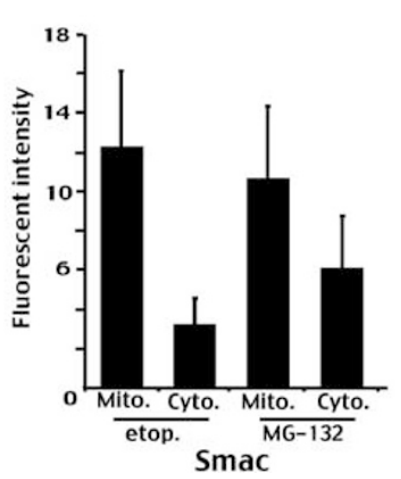

Figure 6 The role of Smac/DIABLO in PIs-dependent apoptosis. (a) E1A/C9DN cells transfected with Smac-specific siRNA or with control siRNA were either incubated or not incubated with MG-132. Appearance of apoptosis was scored by Trypan blue staining (means \pm S.D.; $n=3$ ). (b) Western blot of E1A/C9DN cell lysates either treated or not treated with MG-132 shows the effect of Smac siRNA or control siRNA on caspase-2 processing. (c) Subcellular fractionation of E1A and E1A/C9DN cells treated with etoposide or MG-132 by separating soluble cytosolic fractions (SN) from digitonin insoluble fractions including mitochondria (Pellet). Western immunoblots were performed using the indicated antibodies. Molecular weights are in $\mathrm{kDa}$. (d) E1A/C9DN cells treated with etoposide or MG-132 were fixed, permeabilized and double stained with the anti-Smac and anti-cytochrome $c$ antibodies. (e) Images acquired with the confocal microscope after immunofluorescent labeling were subjected to the quantitative analysis using Metamorph software. Randomly chosen fields in each coverslip were acquired for the analysis. The fluorescent intensity for each pixel subtracted from the background was measured using the appropriate function of the analysis program. Values are normalized to the cell area

shown) and the comparable levels of HDAC4, and PARP processing detected in immunoblot (Figure $6 \mathrm{c}$ ) verified it. The levels of mature Smac were similarly decreased in the mitochondria of etoposide and PIs treated cells compared to the untreated ones. However, the levels of Smac were higher in the cytosol of cells treated with MG-132 compared to 
etoposide (Figure 6c). This increase was not due to alterations in the fractionations procedure as confirmed by F1-ATP synthase and tubulin staining. The fact that in E1A/C9DN cells the level of cytosolic Smac is lower than in E1A cells after treatment with etoposide may be explained by the reduced caspase activity which is important to shutdown the proteasome function during apoptosis. ${ }^{44}$

We confirmed by immunofluorescence analysis that a brighter signal for endogenous Smac can be observed in the cytosol of MG-132-treated E1A/C9DN cells (Figure 6d). To quantify the relative levels of Smac present in the cytosol after MG-132- or etoposide-induced mitochondrial release, confocal images from different fields were selected containing both mitochondrial localized and cytosolic Smac/DIABLO. 400 cells from different fields were individually analyzed and the fluorescence intensity was calculated with respect to the cell area. This analysis shows that the levels of Smac decrease once released into the cytosol, but this decrease is lower in Pls-treated cells. In conclusion, our studies demonstrate that PIs can regulate the amount of cytosolic Smac once released from the mitochondria.

\section{Discussion}

The proteasome is a $2.000 \mathrm{kDa}$ multisubunit cylindrical complex that recognizes and proteolyses proteins that contain multiple ubiquitin molecules. The 195 subunits recognize and subsequently cleave the ubiquitin chain from the protein substrate, whereas the $20 \mathrm{~S}$ subunit (catalytic core) progressively degrades the targeted protein. ${ }^{19}$ Since many proteins that control cell proliferation and apoptosis are degraded after ubiquitination, the proteasome has become an interesting target for anticancer therapy. ${ }^{45}$ Recently, the peptide boronate PS-341/Bortezomib, a reversible inhibitor of the proteasome, has been approved for use in patients with relapse and refractory multiple myeloma. ${ }^{46}$ Interestingly, Bortezomib mechanism of cytotoxicity differs from 60.000 compounds of the National Cancer Institute database. ${ }^{47}$

We have demonstrated that PIs, in contrast to many chemotherapeutic agents, have the unique ability of activating caspases through a mitochondrial pathway that does not need a functional apoptosome. Our studies show that the Bcl-2 family members play a central role in dictating the choice between cell death and survival in response to Pls. It was known that $\mathrm{Bcl}-2$ and $\mathrm{Bcl}-\mathrm{xL}$ can protect against apoptosis induced by Pls. ${ }^{48-50}$ We have demonstrated that not only $\mathrm{Bcl}-$ 2 and $\mathrm{Bcl}-\mathrm{xL}$ can suppress Pls-induced cell death but even the proapoptotic members Bax and Bak are necessary. Overall this scenario indicates that PIs induce the activation of the intrinsic/mitochondrial apoptotic pathway as suggested by other studies. ${ }^{49-53}$ In contrast to other anti-tumor drugs, where $\mathrm{Bcl}-2 / \mathrm{Bcl}-\mathrm{xL}$ overexpression and caspase- 9 inactivation are equally able to suppress caspase activation and cell death, in the case of PIs, only $\mathrm{Bcl}-2 / \mathrm{Bcl}-\mathrm{xL}$ can suppress apoptosis and caspase activation. This strengthened the idea that $\mathrm{Bcl}-2 / \mathrm{Bcl}-\mathrm{xL}$ can control the activation of different caspases independently from caspase-9. ${ }^{21-23}$

The ability of PIs to activate caspases in the absence of a functional caspase- 9 was confirmed by analyzing enzymatic activity, proenzymes and death substrates cleavage in different cellular systems including MEF from mice $-/$ - for caspase-9. Moreover, we have also used a new assay to measure caspase activity in single cells on the OMM, and here again Pls, in contrast to etoposide, were able to trigger caspases activation in the absence of functional apoptosome. This assay allowed us to measure the temporal relationship between caspase activation and mitochondrial depolarization. Previously Rehm et $a{ }^{\beta 1}$, have used the FRET-based sensors to demonstrate that, in response to staurosporine, activation of DEVDases occurs within $10 \mathrm{~min}$ from the onset of depolarization. We have similarly observed that full DEVDase activity in response to etoposide is obtained on the surface of mitochondria in approximately $10 \mathrm{~min}$ after depolarization (10.24 $\min \pm 3.34$ ), whereas MG-132 induces full caspase activity with a certain delay $(27.3 \pm 3.75)$. The reason for this difference is unknown but it could be related to the quicker depolarization induced by MG-132. In caspase- 9 defective cells activation of caspases in response to etoposide was impaired up to $4 \mathrm{~h}$ from mitochondrial depolarization and cells showed reduced dissipation of $\Delta \psi_{\mathrm{m}}$. This observation confirms similar data obtained by using chemicals inhibitors of caspases or Apaf-1-defective cells. ${ }^{30-32}$ The partial dissipation reflects the absence of a caspase-dependent feedback loop on mitochondria. ${ }^{28}$

When apoptosis was induced by PIs in caspase- 9 defective cells, $\Delta \psi_{\mathrm{m}}$ dissipation was similar to that observed in wt cells; caspases activation was also observed, even though with a delay of approximately $120 \mathrm{~min}$. Therefore, two kinetics of caspase activation can be recognized, with caspase- 9 still being required for the rapid caspase activation in response to OMM permeabilization, but dispensable for the slow DEVDases activation.

Our results suggest that, in contrast to etoposide, Pls can induce full mitochondrial depolarization before robust caspase activity. Why can PIs affect mitochondrial function so dramatically? Bortezomib and different types of PIs provoke an elevation of mitochondrial derived reactive oxygen species (ROS), ${ }^{54-57}$ which are critical for the OMM permeabilization, $\Delta \psi_{\mathrm{m}}$ decrease and apoptosis. However, the fact that etoposide also induces ROS production ${ }^{58}$ makes necessary a detailed study on ROS levels generated in single cells after treatment with the different drugs.

We can exclude that the caspase-9 independent apoptosis, triggered by $\mathrm{Pis}$, relies entirely on the compensatory activity of other regulative caspases implicated in the apoptotic process. In fact, caspase-8 inhibition by CrmA only partially affected this apoptotic response (Henderson and Brancolini, unpublished) and downregulation of caspase-2 by siRNA was ineffective (Henderson and Brancolini, unpublished). ${ }^{54}$ Our work indicates that Smac/DIABLO can play a role in regulating caspases activation in the absence of caspase-9. First, we demonstrate that the levels of cytosolic Smac/DIABLO are increased in response to PI treatment. Second, a normal apoptotic response to etoposide can be restored in caspase- 9 defective cells by artificially raising the levels of cytosolic active Smac/DIABLO. Third, Smac siRNA reduced the apoptotic response to Pls.

Once released from mitochondria Smac/DIABLO interacts, through a short amino-terminal sequence, with the IAPs 
relieving their inhibitory effect on caspases. ${ }^{10}$ XIAPs, cIAP1, clAP2 and Livin are E3 ligases containing a carboxy-terminal RING-finger domain that is involved in auto-ubiquitination and ubiquitination of interacting proteins, mediating their degradation via the proteasome. ${ }^{59}$ Different reports have illustrated that Smac/DIABLO is targeted for degradation by the combined action of the E2/E3 ligase BRUCE and XIAP or of ClAP1 and clAP2. ${ }^{33-37,43}$

How could cytosolic Smac activate effector caspases? A possibility is that cancer cells have an intrinsic drive to activate effector caspases, such that functional removal of IAPs triggers apoptosis. This hypothesis has been recently suggested by the identification of XIAP antagonists that specifically target the BIR2 functional region but not the BIR3 and trigger apoptosis in cancer cells. ${ }^{60,61}$ Furthermore, Smac can induce apoptosis in Apollon-deficient cells but not in wild-type cells ${ }^{33}$ and zVAD-fmk can increase the levels of Apollon/Bruce in nonapoptotic cells. ${ }^{37}$

These data together with our results support the hypothesis that in cancer cells caspases are continuously activated at minimal levels and kept in frame by IAPs. ${ }^{60,62,63,17}$ It is clear that further studies are required to confirm this hypothesis. In conclusion, our data indicate that PIs, by sustaining the levels of the IAPs antagonist Smac/DIABLO, can overcome this distal apoptotic checkpoint and they could be powerful drugs to induce cell death of cancer cells that have accumulated mutations in the apoptosome, both as a single agent or in combination with other antitumor treatments.

\section{Materials and Methods}

\section{Culture conditions, transfection and retroviral infection}

All the used cell lines with the exception of the BJ were grown in Dulbecco's modified Eagle's medium (DMEM) supplemented with $10 \%$ fetal calf serum (FCS). In all Trypan blue assays 160-400 cells, from three independent samples, were counted for each data point. Data were represented as arithmetic means \pm S.D. for at least three independent experiments. Trypan blue assays were verified by analyzing the levels of caspases or caspase substrates processing in immunoblotting. E1A/Bcl-2 and E1A/C9DN/Bcl-2 cells were generated by retroviral infection. ${ }^{18} \mathrm{Smac}$ siRNA CCACATATGCGTTGATTGAAGCTAT (bp 275-299) and control siRNA CCAGTATTTGCTTAGGAAGCACTAT (scrambled) were purchased from Invitrogen. Cells were transfected $24 \mathrm{~h}$ after plating by adding to the medium OptiMEM containing lipofectamine (Invitrogen) plus the siRNAs.

\section{Plasmids generation}

The pEGFPC3-HA-TMBcl-xL was generated by subcloning the HindIIIEcoRI HA tag fragment from pcDNA3HA into pEGFPC3 (Invitrogen). The $\mathrm{Bcl}-\mathrm{xL}$ transmembrane coding CDNA was amplified by PCR from pGDSV7-Bcl-xL using specific primers and inserted as an EcoRl/Sall fragment. Next the DEVD coding sequence was inserted into the pEGFPC3-HA-TMBcl-xL plasmid. The oligonucleotides were annealed and ligated into the plasmid backbone as an Xhol/Hindll fragment.

In vitro mutagenesis (Invitrogen) was performed to obtain pEGFPC3DEVA-HA-TMBCl-xL (GFP-AD-TM) and pEGFPC3DEVA-HA(-D)-TMBcl$\mathrm{xL}$ (GFP-AA-TM) plasmids. pUC19-Ub- $\Delta 71-\mathrm{mSmac} / \mathrm{DIABLO}$ was generated by an overlapping PCR strategy from pUC19-Ub- $\Delta 53$ $\mathrm{mSmac} / \mathrm{DIABLO}$. The Ub- $\Delta 71-\mathrm{mSmac} / \mathrm{DIABLO} \mathrm{PCR}$ product was digested by $\mathrm{Hindll} / \mathrm{XhOl}$ to insert it into the ubiquitin $\mathrm{C}$ promotercontaining expression vector pUC19 (courtesy of $P$ Liston). pET32a $(+)$ $\triangle 53-\mathrm{mSmac} / \mathrm{DIABLO}$ was generated by amplifying the coding region of mouse Smac/DIABLO by PCR. pGEX4T1- $453-\mathrm{mSmac} / \mathrm{DIABLO}$ was generated by subcloning the $\triangle 53-\mathrm{mSmac} / \mathrm{DIABLO}$ coding region from

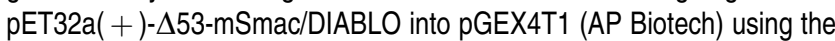
BamHI/Xhol sites.

\section{Time-lapse confocal fluorescence microscopy}

For time-lapse imaging, cells were grown on $35 \mathrm{~mm}$ glass-bottom dishes (Wilco BV) and microinjected using the automated injection system (Zeiss) with $2 \mathrm{ng}$ of plasmid DNA. After $3 \mathrm{~h}$ cells were treated with the $\Delta \psi_{\mathrm{m}}$ sensitive dye-TMRM, ${ }^{29}$ (20 nM final) and etoposide $(50 \mu \mathrm{M})$ or MG-132 $(2.5 \mu \mathrm{M})$; the media was then covered with embryo-tested mineral oil to prevent evaporation. After 3-6h of treatment the culture dishes were subjected to time-lapse analysis. Imaging of GFP and TMRM fluorescence was monitored every 2 min using a confocal microscope equipped with a $488 \mathrm{~nm}$ argon laser, a $543 \mathrm{~nm}$ HeNe laser and a $63 \times$ oil fluorescence objective.

\section{Image processing and remodeling of fluorescence kinetics}

The image analysis was performed using the MetaMorph 6.04. software. For TMRM analysis in single cells, fluorescent mitochondria (MT) were analyzed by drawing a region around them and by measuring the total brightness (integrated fluorescence intensity or $\mathrm{I}_{\mathrm{TMRM}}$ ) of such a region. The background to be subtracted from the $\|_{\text {TMRM }}\left(B_{\text {TMRM }}\right)$ was calculated by using a ROI positioned in a nonfluorescent region according to the following equation:

$$
\mathrm{Bk}_{\mathrm{TMRM}}=\left(\mathrm{II}_{\mathrm{ROI}} / \text { Area }_{\mathrm{ROI}}\right) * \text { Area }_{\mathrm{MT}} .
$$

Finally, the background-corrected $\|_{T M R M}$ values were presented as the percentage of the average of the 29 values detected before the $\|_{\text {TMRM }}$ started decreasing. The $\|_{\text {TMRM }}$ values have been taken for $60 \mathrm{~min}$ before and $120 / 240 \mathrm{~min}$ after the beginning of the $\Delta \psi_{\mathrm{m}}$ decrease (set to min, 0 ).

The release kinetics of GFP have been measured as the S.D. from the average pixel intensity of a ROI positioned on the mitochondria and cytosol of individual cells. Mitochondrial localized TM-DD-GFP (punctuate) contributes to a high S.D. of pixel intensities, whereas homogeneously distributed GFP (diffuse) is represented by a low S.D. To examine the relationship between $\Delta \psi_{\mathrm{m}}$ loss and caspase activation better, the punctuate-diffuse GFP values have been shown as the inverse value of S.D. after background subtraction (1/S.D. $=y)$. For direct comparisons and statistical analyses, single cell standard deviation traces were transformed in a $0-100 \%$ scale in which $0 \%$ equals to the first $y$ punctuate value $\left(y_{M T}\right)$ and $100 \%$ equals the first complete diffusion value ( $\left.y_{\text {diff }}\right)$ according to the following equation:

$$
y_{(0-100 \%)}=100 *\left(y-y_{\mathrm{MT}}\right) /\left(y_{\text {diff }}-y_{\mathrm{MT}}\right)
$$

For analyzing cells that present $\Delta \psi_{\mathrm{m}}$ decrease but do not release GFP in the cytosol, a relation between $\|_{\mathrm{GFP}}$ and $\mathrm{SD}_{\mathrm{GFP}}$ diff has been calculated from the linear tredline of the values recovered from 20 cells that do release GFP:

$$
\mathrm{SD}_{\mathrm{GFP} \text { diff }}=2706,8 * \mathrm{II}_{\mathrm{GFP}}-215,66
$$

Such an equation has been used to calculate the hypothetical $\mathrm{SD}_{\mathrm{GFP}}$ diff 
that a cell, with given $\|_{\mathrm{GFP}}$, could reach. After background subtraction it was possible to calculate the $y_{\text {diff }}$ necessary to scale the values from 0 to 100 .

\section{Antibody production and Western blotting}

Rabbits were immunized with recombinant histidin-tagged Smac/DIABLO $\Delta 53$ purified from Escherchia coli. For anti-Smac/DIABLO antibody purification from antiserum, Smac/DIABLO was fused to GST and crosslinked to glutathione-Sepharose as previously described. ${ }^{64}$

For Western blotting, proteins were transferred to a $0.2 \mu \mathrm{m}$ pore sized nitrocellulose membrane and incubated with anti-caspase- $2,{ }^{18}$ anti-Smac/ DIABLO anti-GFP, ${ }^{64}$ anti-caspase-8 (Alexis), anti-caspase-7 (Cell Signalling), anti-p85 PARP fragment (Promega), anti-PARP (Cell Signalling), anti-tubulin, anti-Bid (Cell Signalling), anti- $\beta$-catenin (Tranduction lab), anti-HDAC4 (40), and anti- $\beta$-gal (Promega) antibodies.

\section{Immunofluorescence microscopy}

For indirect immunofluorescence microscopy, cells were fixed with $3 \%$ paraformaldehyde in PBS for $20 \mathrm{~min}$ at room temperature. Fixed cells were washed with PBS/0.1 M glycine, $\mathrm{pH} 7.5$, and then permeabilized with $0.1 \%$ Triton X 100 in PBS for 5 min. The coverslips were treated with the anti-cytochrome $c$ (Promega) or anti-Smac antibodies, diluted in PBS, for $45 \mathrm{~min}$ in a moist chamber at $37^{\circ} \mathrm{C}$. They were then washed with PBS twice, and incubated with 488 or 543 Alexa-conjugated secondary antibodies (Molecular Probes), for $30 \mathrm{~min}$ at $37^{\circ} \mathrm{C}$.

\section{Acknowledgements}

We thank P Liston (Ottawa, Ontario, Canada) for Smac/DIABLO/ubiquitin plasmids, A Chiandetti (Novara, Italy) for XIAP plasmid, M Stebel (Trieste, Italy) for the immunization of rabbits and G Lippe (Udine, Italy) for anti-F1. ATP synthase antibody. We also thank P Baldo (Aviano, PN, Italy) for helping in some experiments, $L$ Scorrano (Padova, Italy) for providing MEFs and for critically reading the manuscript, $Y$ Lazebnik and RA Flavell for caspase-9 mutant cells and P Bernardi (Padova, Italy) for helpful suggestions. Our work is supported by grants from AIRC (Associazione Italiana per la Ricerca sul Cancro), CNR/MIUR Legge 449/97-DM 20/10/ 2000) and FIRB. CH received a fellowship from the Fondazione Italiana per la Ricerca sul Cancro.

\section{References}

1. Debatin K (2000) Activation of apoptosis pathways by anticancer treatment. Toxicol Lett. 112-113: 41-48

2. Makin G and Dive $C$ (2001) Apoptosis and cancer chemotherapy. Trends Cell Biol. 11: S22-S26

3. Cryns V and Yuan J (1998) Proteases to die for. Genes Dev. 12: 1551-1570

4. Boatright KM and Salvesen GS (2003) Mechanisms of caspase activation. Curr. Opin. Cell Biol. 15: 725-731

5. Shi $Y$ (2004) Caspase activation: revisiting the induced proximity model. Cell 117: $855-858$

6. Fischer U, Janicke RU and Schulze-Osthoff K (2003) Many cuts to ruin: a comprehensive update of caspase substrates. Cell Death Differ. 10: 76-100

7. Jiang X and Wang X (2004) Cytochrome $C$-mediated apoptosis. Annu. Rev. Biochem. 73: 87-106

8. Cory S, Huang DC and Adams JM (2003) The Bcl-2 family: roles in cell survival and oncogenesis. Oncogene 22: 8590-8607
9. Scorrano L and Korsmeyer SJ (2003) Mechanisms of cytochrome c release by proapoptotic BCL-2 family members. Biochem. Biophys. Res. Commun. 304: 437-444

10. Salvesen GS and Duckett CS (2002) IAP proteins: blocking the road to death's door. Nat. Rev. Mol. Cell Biol. 3: 401-410

11. Debatin KM, Poncet D and Kroemer G (2002) Chemotherapy: targeting the mitochondrial cell death pathway. Oncogene 21: 8786-8803

12. Cecconi F, Alvarez-Bolado G, Meyer BI, Roth KA and Gruss P (1998) Apaf1 (CED-4 homolog) regulates programmed cell death in mammalian development. Cell 94: 727-733

13. Fearnhead HO, Rodriguez J, Govek EE, Guo W, Kobayashi R, Hannon G and Lazebnik YA (1998) Oncogene-dependent apoptosis is mediated by caspase9. Proc. Natl. Acad. Sci. USA 95: 13664-13669

14. Hakem R, Hakem A, Duncan GS, Henderson JT, Woo M, Soengas MS, Elia A, de la Pompa JL, Kagi D, Khoo W, Potter J, Yoshida R, Kaufman SA, Lowe SW, Penninger JM and Mak TW (1998) Differential requirement for caspase 9 in apoptotic pathways in vivo. Cell 7: 339-345

15. Lassus $P$, Opitz-Araya $X$ and Lazebnik $Y$ (2002) Requirement for caspase-2 in stress-induced apoptosis before mitochondrial permeabilization. Science 297: 1352-1354

16. Soengas MS, Alarcon RM, Yoshida H, Giaccia AJ, Hakem R, Mak TW and Lowe SW (1999) Apaf-1 and caspase-9 in p53-dependent apoptosis and tumor inhibition. Science 284: 156-159

17. Yoshida H, Kong YY, Yoshida R, Elia AJ, Hakem A, Hakem R, Penninger JM and Mak TM (1998) Apaf1 is required for mitochondrial pathways of apoptosis and brain development. Cell 94: 739-750

18. Henderson C, Mizzau M, Paroni G, Maestro R, Schneider C and Brancolini C (2003) Role of caspases, Bid, and p53 in the apoptotic response triggered by histone deacetylase inhibitors trichostatin-A (TSA) and suberoylanilide hydroxamic acid (SAHA). J. Biol. Chem. 278: 12579-12589

19. Hershko A and Ciechanover A (1998) The ubiquitin system. Ann. Rev. Biochem. 67: 425-479

20. Lee DH and Goldberg AL (1998) Proteasome inhibitors: valuable new tools for cell biologists. Trends Cell Biol. 8: 397-403

21. Ekert PG, Read SH, Silke J, Marsden VS, Kaufmann H, Hawkins CJ, Gerl R, Kumar S and Vaux DL (2004) Apaf-1 and caspase-9 accelerate apoptosis, but do not determine whether factor-deprived or drug-treated cells die. J. Cell Biol. 165: 835-842

22. Marsden VS, Ekert PG, Van Delft M, Vaux DL, Adams JM and Strasser A (2004) Bcl-2-regulated apoptosis and cytochrome $c$ release can occur independently of both caspase-2 and caspase-9. J. Cell Biol. 165: 775-780

23. Marsden VS, O'Connor L, O'Reilly LA, Silke J, Metcalf D, Ekert PG, Huang DC, Cecconi F, Kuida K, Tomaselli KJ, Roy S, Nicholson DW, Vaux DL, Bouillet P, Adams JM and Strasser A (2002) Apoptosis initiated by Bcl-2-regulated caspase activation independently of the cytochrome c/Apaf-1/caspase- 9 apoptosome. Nature 419: 634-637

24. Wei MC, Zong WX, Cheng EH, Lindsten T, Panoutsakopoulou V, Ross AJ, Roth KA, MacGregor GR, Thompson CB and Korsmeyer SJ (2001) Proapoptotic BAX and BAK: a requisite gateway to mitochondrial dysfunction and death. Science 292: 727-730

25. Bernardi P, Petronilli V, Di Lisa F and Forte M (2001) A mitochondrial perspective on cell death. Trends Biochem. Sci. 26: 112-117

26. Ly JD, Grubb DR and Lawen A (2003) The mitochondrial membrane potential (deltapsi(m)) in apoptosis; an update. Apoptosis 8: 115-128

27. Heiskanen KM, Bhat MB, Wang HM, Ma J and Nieminen AL (1999) Mitochondrial depolarization accompanies cytochrome $c$ release during apoptosis in PC6 cells. J. Biol. Chem. 26: 5654-5658

28. Ricci JE, Munoz-Pinedo C, Fitzgerald P, Bailly-Maitre B, Perkins GA, Yadava $\mathrm{N}$, Scheffler IE, Ellisman MH and Green DR (2004) Disruption of mitochondrial function during apoptosis is mediated by caspase cleavage of the p75 subunit of complex I of the electron transport chain. Cell 117: 773-786

29. Scorrano L, Petronilli V, Di Lisa F and Bernardi P (1999) Commitment to apoptosis by GD3 ganglioside depends on opening of the mitochondrial permeability transition pore. J. Biol. Chem. 274: 22581-22585

30. Dussmann H, Rehm M, Kogel D and Prehn JH (2003) Outer mitochondrial membrane permeabilization during apoptosis triggers caspase-independent mitochondrial and caspase-dependent plasma membrane potential depolarization: a single-cell analysis. J. Cell Sci. 116: 525-536 
31. Rehm M, Dussmann H and Prehn JH (2003) Real-time single cell analysis of Smac/DIABLO release during apoptosis. J. Cell Biol. 162: 1031-1043

32. Waterhouse NJ, JGoldstein JC, von Ahsen O, Schuler M, Newmeyer DD and Green DR (2001) Cytochrome c maintains mitochondrial transmembrane potential and ATP generation after outer mitochondrial membrane permeabilization during the apoptotic process. J. Cell Biol. 153: 319-328

33. Hao Y, Sekine K, Kawabata A, Nakamura H, Ishioka T, Ohata H, Katayama R, Hashimoto C, Zhang X, Noda T, Tsuruo T and Naito M (2004) Apollon ubiquitinates SMAC and caspase-9, and has an essential cytoprotection function. Nat. Cell Biol. 6: 849-860

34. MacFarlane M, Merrison W, Bratton SB and Cohen GM (2002) Proteasomemediated degradation of Smac during apoptosis: XIAP promotes Smac ubiquitination in vitro. J. Biol. Chem. 277: 36611-36616

35. Bartke T, Pohl C, Pyrowolakis G and Jentsch S (2004) Dual role of BRUCE as an antiapoptotic IAP and a chimeric E2/E3 ubiquitin ligase. Mol Cell 14: $801-811$

36. Hu S and Yang X (2003) Cellular inhibitor of apoptosis 1 and 2 are ubiquitin ligases for the apoptosis inducer Smac/DIABLO. J. Biol. Chem. 278: 10055-10060

37. Qiu XB and Goldberg AL (2005) The membrane-associated inhibitor of apoptosis protein, BRUCE/Apollon, antagonizes both the precursor and mature forms of Smac and caspase-9. J. Biol. Chem. 280: 174-182

38. Wilkinson JC, Wilkinson AS, Scott FL, Csomos RA, Salvesen GS and Duckett CS (2004) Neutralization of Smac/Diablo by inhibitors of apoptosis (IAPs): a caspase-independent mechanism for apoptotic inhibition. J. Biol. Chem. 279: 51082-51090

39. Hunter AM, Kottachchi D, Lewis J, Duckett CS, Korneluk RG and Liston P (2003) A novel ubiquitin fusion system bypasses the mitochondria and generates biologically active Smac/DIABLO. J. Biol. Chem. 278: 7494-7499

40. Chai J, Du C, Wu JW, Kyin S, Wang X and Shi Y (2000) Structural and biochemical basis of apoptotic activation by Smac/DIABLO. Nature 406: 855-862

41. Srinivasula SM, Datta $P$, Fan XJ, Fernandes-Alnemri $F$, Huang $Z$ and Alnemri ES (2000) Molecular determinants of the caspase-promoting activity of Smac/DIABLO and its role in the death receptor pathway. J. Biol. Chem. 275: 36152-36157

42. Srinivasula SM, Hegde $R$, Saleh A, Datta $P$, Shiozaki E, Chai J, Lee RA Robbins PD, Fernandes-Alnemri T, Shi Y and Alnemri ES (2001) A conserved XIAP-interaction motif in caspase- 9 and Smac/DIABLO regulates caspase activity and apoptosis. Nature 410: 112-116

43. Wu G, Chai J, Suber TL, Wu JW, Du C, Wang X and Shi Y (2000) Structural basis of IAP recognition by Smac/DIABLO. Nature 408: 1008-1012

44. Sun XM, Butterworth M, MacFarlane M, Dubiel W, Ciechanover A and Cohen GM 2004 Caspase activation inhibits proteasome function during apoptosis. Mol. Cell. 14: 81-93

45. Almond JB and Cohen GM (2002) The proteasome: a novel target for cancer chemotherapy. Leukemia 16: 433-443

46. Adams J (2004) The proteasome: a suitable antineoplastic target. Nat. Rev. Cancer 4: 349-360

47. Adams J, Palombella VJ, Sausville EA, Johnson J, Destree A, Lazarus DD, Maas J, Pien CS, Prakash S and Elliott PJ (1999) Proteasome inhibitors: a novel class of potent and effective antitumor agents. Cancer Res. 59: 2615-2622

48. Lopes UG, Erhardt P, Yao R and Cooper GM (1997) p53-dependent induction of apoptosis by proteasome inhibitors. J. Biol. Chem. 272: 12893-12896

49. Marshansky V, Wang X, Bertrand R, Luo H, Duguid W, Chinnadurai G, Kanaan $\mathrm{N}, \mathrm{Vu} \mathrm{N}$ and $\mathrm{Wu} \mathrm{J}$ (2001) Proteasomes modulate balance among proapoptotic and antiapoptotic Bcl-2 family members and compromise functioning of the electron transport chain in leukemic cells. J. Immunol. 166: 3130-3142

50. Wagenknecht $B$, Hermisson M, Groscurth $\mathrm{P}$, Liston $\mathrm{P}$, Krammer $\mathrm{PH}$ and Weller M (2000) Proteasome inhibitor-induced apoptosis of glioma cells involves the processing of multiple caspases and cytochrome $c$ release. J. Neurochem. 75: 2288-2297

51. Dewson G, Snowden RT, Almond JB, Dyer MJ and Cohen GM (2003) Conformational change and mitochondrial translocation of Bax accompany proteasome inhibitor-induced apoptosis of chronic lymphocytic leukemic cells. Oncogene 22: 2643-2654

52. Jana NR, Dikshit P, Goswami A and Nukina N (2004) Inhibition of proteasomal function by curcumin induces apoptosis through mitochondrial pathway. J. Biol. Chem. 279: 11680-11685

53. Mitsiades N, Mitsiades CS, Poulaki V, Chauhan D, Fanourakis G, Gu X, Bailey C, Joseph M, Libermann TA, Treon SP, Munshi NC, Richardson PG, Hideshima T and Anderson KC (2002) Molecular sequelae of proteasome inhibition in human multiple myeloma cells. Proc. Natl. Acad. Sci. USA 99: 14374-14379

54. Fribley A, Zeng $Q$ and Wang CY (2004) Proteasome inhibitor PS-341 induces apoptosis through induction of endoplasmic reticulum stress-reactive oxygen species in head and neck squamous cell carcinoma cells. Mol. Cell Biol. 24: 9695-9704

55. Ling YH, Liebes L, Zou Y and Perez-Soler R (2003) Reactive oxygen species generation and mitochondrial dysfunction in the apoptotic response to Bortezomib, a novel proteasome inhibitor, in human $\mathrm{H} 460$ non-small cell lung cancer cells. J. Biol. Chem. 278: 33714-33723

56. Sullivan PG, Dragicevic NB, Deng JH, Bai Y, Dimayuga E, Ding Q, Chen $Q$, Bruce-Keller AJ and Keller JN (2004) Proteasome inhibition alters neural mitochondrial homeostasis and mitochondria turnover. J. Biol. Chem. 279: 20699-20707

57. Yu C, Rahmani M, Dent P and Grant S (2004) The hierarchical relationship between MAPK signaling and ROS generation in human leukemia cells undergoing apoptosis in response to the proteasome inhibitor Bortezomib. Exp. Cell Res. 295: 555-566

58. Kurosu T, Fukuda T, Miki T and Miura O (2003) BCL6 overexpression prevents increase in reactive oxygen species and inhibits apoptosis induced by chemotherapeutic reagents in B-cell lymphoma cells. Oncogene 22: 4459-4468

59. Zhang HG, Wang J, Yang X, Hsu HC and Mountz JD (2004) Regulation of apoptosis proteins in cancer cells by ubiquitin. Oncogene 23: 2009-2015

60. Schimmer AD, Welsh K, Pinilla C, Wang Z, Krajewska M, Bonneau MJ, Pedersen IM, Kitada S, Scott FL, Bailly-Maitre B, Glinsky G, Scudiero D, Sausville E, Salvesen G, Nefzi A, Ostresh JM, Houghten RA and Reed JC (2004) Small-molecule antagonists of apoptosis suppressor XIAP exhibit broad antitumor activity. Cancer Cell 5: 25-35

61. Wang Z, Cuddy M, Samuel T, Welsh K, Schimmer A, Hanaii F, Houghten R, Pinilla C and Reed JC (2004) Cellular, biochemical, and genetic analysis of mechanism of small molecule IAP inhibitors. J. Biol. Chem. 279: 48168-48176

62. Tenev T, Marani M, McNeish I and Lemoine NR (2001) Pro-caspase-3 overexpression sensitises ovarian cancer cells to proteasome inhibitors 8 : 256-264

63. Yang L, Cao Z, Yan H and Wood WC (2003) Coexistence of high levels of apoptotic signaling and inhibitor of apoptosis proteins in human tumor cells: implication for cancer specific therapy. Cancer Res. 63: 6815-6824

64. Paroni G, Mizzau M, Henderson C, Del Sal G, Schneider C and Brancolini C (2004) Caspase-dependent regulation of histone deacetylase 4 nuclearcytoplasmic shuttling promotes apoptosis. Mol. Biol. Cell 15: 2804-2818 